\title{
Nuclear Policy-Nuclear Fuels for Peaceful, Safer Co-generation and Environmentally Benign Applications
}

\author{
Syazwani Mohd Fadzil', Shafi Qureshi ${ }^{2}$, Sekhar Basu ${ }^{3}$, K. Kasturirangan ${ }^{4}$, \\ Anil Kakodkar ${ }^{3}$, Kushal D. Badgujar ${ }^{5}$ *,Prakash M. Duxit ${ }^{6}$ \\ ${ }^{I}$ Senior Lecturer, Department of Applied Physics, Universiti Kebangsaan Malaysia. \\ ${ }^{2}$ Professor in Electrical Engineering at IIT Kanpur, India. \\ ${ }^{3}$ Nuclear Scientist at Bhabha Atomic Research Centre, Mumbai, India. \\ ${ }^{4}$ Former Chairman of the Indian Space Research Organization \\ ${ }^{5}$ Post-doctoral Research Associate, BARC, Mumbai, Maharashtra, India. \\ ${ }^{6}$ Professor in Mechanical Engineering at IIT Kanpur, India. \\ *Corresponding authorE-mail:kushal.8@live.com
}

\begin{abstract}
Here, safer nuclear fuels which can sustain in the high temperature and fluence environment of the reactor core are investigated to utilize nuclear energy peacefully. At Nuclear Fuel Complex in Hyderabad, nuclear fuels are being manufactured which are best suited for high temperature and fluence environment of the reactor core even in accidental scenarios. In this paper, nuclear fuels manufactured at NFC, Hyderabad are presented. The developed nuclear fuels have higher equivalent hydraulic diameter and breeding capability to produce $\mathbf{U}^{\mathbf{2 3 3}}$. Nuclear fuels having higher equivalent hydraulic diameter reduce the reactor core temperature substantially. These fuels have negative temperature coefficient of reactivity. Thus, in case of an accident, the fuel temperature never exceeds the safety limit. Therefore, the thermal heat available across the secondary of a heat exchanger can be utilized for different industrial processes. This allows the development of key technologies, such as safer co-generation of electricity and Hydrogen. The product Hydrogen gas has been utilized in many ways for different applications. Moreover, the processing of iron ore with the energy obtained from the IHX secondary side, eliminates the burning of coals and $\mathrm{CO}_{2}$ emissions into the environment. Several radioisotopes have been developed for medical applications from spent fuel.
\end{abstract}

Keywords: Annular fuels Nuclear Fuels; Autonomous management; Crystallography.

\section{Introduction}

One of the important safety requirements for a nuclear reactor is lowering the operating temperature of the reactor core. The higher operating temperatures of nuclear fuel can lead to melting of the reactor core in case of an accident. The conventional nuclear fuel pins which were used at Fukushima Daiichi nuclear power plant make use of cylindrical fuel pellets did not satisfy safety criteria set by Atomic Energy Regulatory Board (AERB).Here, nuclear fuel designs have been put forward, which are useful for cogeneration of electricity and process heat. In this paper, the necessity to use safe nuclear fuels for advanced nuclear power plants has been explained in section 2 with the help of major accidents that occurred in history. Section 3 describes the necessity of nuclear energy with safer fuels. Section 4 provides nuclear fuel manufacturing process. Section $5 \& 6$ describe nuclear materials used in the reactor and design for nuclear fuels with their advantages. Section 7 provides choices of coolant used for power plant. Section 8 delineates some safety and stability issues envisaged for the nuclear power plant. Section 9 explains the peaceful usage of nuclear energy with the three-stage recycling method. Section 10 and 11 describes the peaceful applications developed from nuclear energy. Finally, the section 12 draws the conclusion.

\section{Highlights of major accidents}

Scientists are optimistic about the usage of nuclear power even after several accidents. Out of the number of nuclear accidents, three major nuclear accidents which occurred in history are briefly explained in following subsections.

\subsection{RBMK at Chernobyl}

The Chernobyl nuclear disaster that occurred in the midnight of April26,1986 is illustrated below.

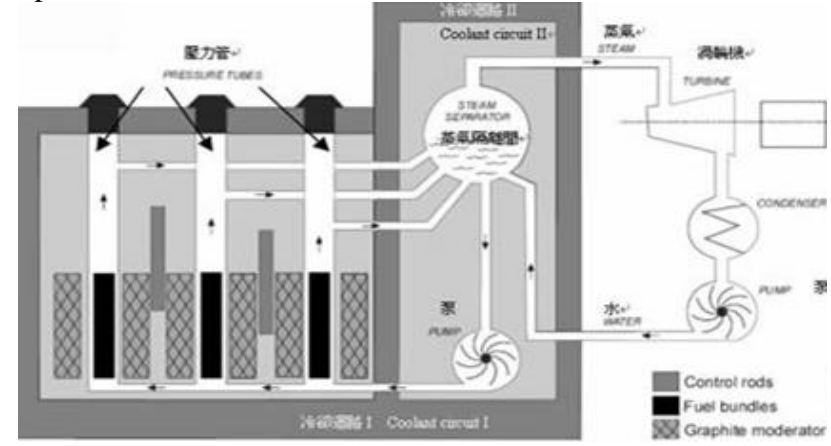

Fig.1: Chernobyl reactor core [1] 
The reactor core built at Chernobyl was a graphite-moderated pressure tube or channel type BWR core (Fig.1). The chronological sequence of events for the accident at Chernobyl has been explained in details by K.D. Badgujar [2]. Some of the peculiar facts that lead to Chernobyl accident are mentioned below:

(1)The Chernobyl reactor core was operated in an over-moderated region with positive coefficient of reactivity. Thus, overheating of the reactor coolant caused an increase in the fraction of steam void that further lead to a large amplitude step increase in reactivity.

(2) The introduction of a sufficient number of neutron absorbers control rods inside the core would have made the positive void coefficient of reactivity less positive or even taken the reactor in the un-moderated region.

(3) The Chernobyl RBMK core was a large diameter core with different parts of the core decoupled from one another. This caused controlling reactor power distribution difficult at low power when a small fraction of control rod is inserted into the core (Fig.1).

The ensuing positive void coefficient of reactivity triggered two neurotics pulses (of length $4 \mathrm{~s}$ ) which eventually raised normalized reactor power by 2000 times. The prompt fission energy liberated after the accident can be calculated with following equation

$$
\frac{\mathrm{dn}(\mathrm{t})}{\mathrm{dt}}=\mathrm{n}(0) \frac{\mathrm{K}_{0}-\beta}{\Lambda} .
$$

Here, $\Lambda$ is called neutron regeneration time $=0.064 \mathrm{~ms}$ and is known as effective delayed neutron fraction [3].The simulation studies by Fletcher et al. revealed that reactivity jumped rapidly to $\sim 1.5 \$$ at the highest power level during the transient [4]. This is due to the rise in positive void coefficient reactivity value by 20 $30 \mathrm{pcm}$ after insertion of control rods which introduced the negative temperature coefficient of reactivity. The solution of equation (1) with an initial value of $n(0)=200 \mathrm{MWt}$ is

$$
\mathrm{n}(\mathrm{t})=\mathrm{n}(0) \exp \left(\frac{\mathrm{K}_{0}-\beta}{\Lambda} \mathrm{t}\right),
$$

when peak power $n(T)$ is $384 \mathrm{GW}$ at $\mathrm{T}=4 \mathrm{~s}$, the step change in reactivity from equation (2) would be $\mathrm{K}_{0}=\$ 1.2$ which is close to the estimate of $\mathrm{K}_{0}=\$ 1.5$ by $\mathrm{H}$. Mochizuki' [5] analysis. By integrating equation (2) over the period of reactivity excursion, the total energy released after the power excursion can be estimated as,

$$
\mathrm{Q}(\mathrm{T})=\mathrm{q}(0) \frac{\Lambda}{\mathrm{K}_{0}-\beta} \exp \left(\frac{\mathrm{K}_{0}-\beta}{\Lambda} \mathrm{T}\right)=203 \mathrm{GJ} .
$$

This is slightly smaller than the Soviet estimate of 239GJ [6]. The RELAP-5 simulations by Fletcher reveals the estimate of energy $\mathrm{Q}(\mathrm{T})$ as $169 \mathrm{GJ}$, and power $\mathrm{n}(\mathrm{T})=391 \mathrm{GWt}$. But $\mathrm{UO}_{2}$ melts at an average energy density $1 \mathrm{MJ} / \mathrm{Kg}$. Thus, the Chernobyl reactor core crossed the limit for melting the reactor core. Approximately, $95 \%$ of the molten reactor fell down to the bottom of the reactor core, and $5 \%$ of the fuel was shot upward from the fuel pins of the reactor core. With thermal to the mechanical conversion efficiency of $5 \%$, a calculation shows that mechanical energy $>0.5$ GJ would have lifted the $1000 \mathrm{MG}$ reactor shield blocks by $50 \mathrm{~m}$ high up in the sky! This massive thermal explosion blew-up reactor cover assembly and relinquished following large inventory of radioactive fission products into the open atmosphere as enlisted in the Table 1 [7].

Table 1: Radioactivity released into the environment

\begin{tabular}{ccc}
\hline Nuclide/Fuel & Release Fraction in \% & Radioactivity (MCi) \\
\hline Nobel Gases & 100 & $190 \pm 20$ \\
$\mathrm{I}^{131}$ & $55 \pm 5$ & $45 \pm 5$ \\
$\mathrm{Cs}^{137}$ & $33 \pm 10$ & $2.3 \pm 0.7$ \\
$\mathrm{Sr}^{90}, \mathrm{Y}^{90}$ & 4.0 & $2.8 \pm 0.8$ \\
Fuel & $3.5 \pm 0.5$ &
\end{tabular}

The radioactive lighter material was carried by wind in the parts of Ukraine, Belarus, Russia, Scandinavia and Europe. The conse- quences of this accident after the massive fire and a large amount of radioactivity release in the atmosphere are listed below:

1. Victims- 31died, 500 hospitalized (out of which 203 people received $>100$ rem. dose)

2. 24,000 people those who received radiation dose 35 to 50 rem each, were evacuated from the exclusive zone within the radius of $15 \mathrm{~km}$ from the plant.

3. 1,35,000 people were evacuated from an exclusive zone with a radius of $30 \mathrm{~km}$.

\subsection{PWR at TMI-2}

In this accident which occurred in PWR at Three Mile Island (TMI), the peak fuel temperature in second unit increased above $1273 \mathrm{~K}$, initiated cladding oxidation exothermic reaction. This exothermic reaction released $6.5 \mathrm{MJ} / \mathrm{Kg}$ of cladding material. With the following correlation, the mass of cladding oxidized per unit area exposed to steam at temperature $\mathrm{T}$ in time interval $\mathrm{t}$ can be determined as,

$$
\mathrm{W}^{2}=A \mathrm{e}^{-\frac{\mathrm{B}}{\mathrm{RT}} \mathrm{t}},
$$

where constant $\mathrm{R}$ is universal gas constant (8.314), $\mathrm{A}=294 \mathrm{~kg}^{2} /$ $\mathrm{m}^{4} \mathrm{~s}, \mathrm{~B}=167 \mathrm{MJ}$. kg. mol .Consider the Zion PWR plant parameters. The total surface area of fuel cladding is $5400 \mathrm{~m}^{2}$. Assuming that the total surface area is exposed to steam for 5 minutes, will yield $\mathrm{W}=0.322 \mathrm{~kg} / \mathrm{m}^{2}$, i.e. $1738.8 \mathrm{Kg}$ of cladding material will be oxidized. Because two moles of Hydrogen are liberated per mole of cladding material, the mass of Hydrogen $\left(\mathrm{H}_{2}\right)$ produced is $\left(\mathrm{M}_{h}\right)$ is $76.9 \mathrm{~kg}$. A significant concern and fear developed among public domain was that Hydrogen bubble might ignite but this did not happen (Fig.2).

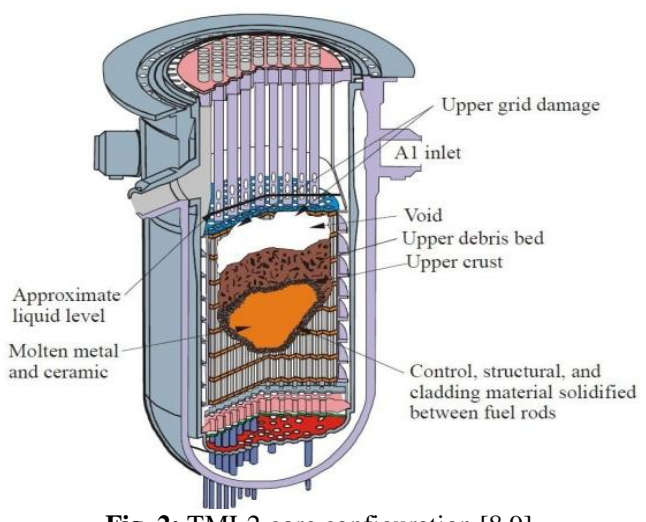

Fig. 2: TMI-2 core configuration $[8,9]$

The TMI-2 accident the scenario has been simulated with Melcor code [10]. The reactor coolant system pressure build-up for the first 6 periods is delineated in Fig.3. A detailed analysis has been also performed by the Electric Power Research Institute [11].

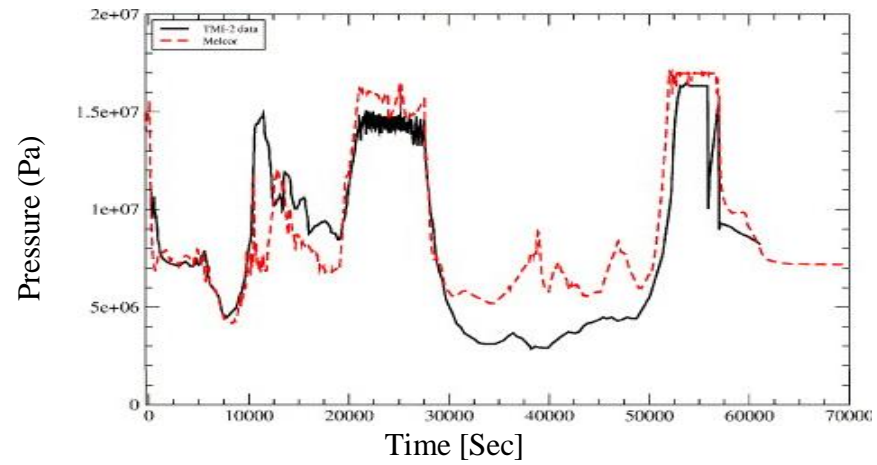

Fig. 3: Reactor coolant pressure buildup history [10] 
The TMI-2 accident occurred due to ignorance whereas Chernobyl accident occurred due to an intentional violation of the operating procedure. The TMI-2 unit had minimal actual radiological consequences, with no serious radiation exposure in the public domain. A similar incident took place in Davis-Besse plant also. The Westinghouse built similar plants at Kori, a suburban village in Busan in South Korea which suffered station blackout (SBO) event on February 9, 2012.

\subsection{BWRs at Fukushima Daiichi}

At Fukushima Daiichi, a giant earthquake of Richter scale 9.0 followed within an hour by tsunami waves of 10 to $14 \mathrm{~m}$ struck the nuclear plant controlled by TEPCO on 11th March, 2011. At that time, the power plant site had unit 1,2, 3 in operation and unit 4,5,6 in a refuelling outage stage. These units were (Boiling Water Reactor) BWRs constructed by General Electric etc, which started operation between 1971 to 1979 with a power rating of 439 to 1067 MWe (Fig. 4). After the earthquake within a few seconds, all the three reactors were shut down by using control blades. The earthquake also disrupted the electrical power supply from the external grid. Moreover, the diesel generators stopped functioning after the tsunami waves hit the Fukushima Daiichi power plant, which eventually lead to SBO event. After the failure of the reactor core isolation cooling system, TEPCO plant workers decided to inject seawater into the reactor core. Because of delay in the injection of seawater into the reactor core of unit 1 , unit 2 , unit 3 , some segments of the fuel rod were exposed without the presence of coolant which caused overheating of the fuel rods.

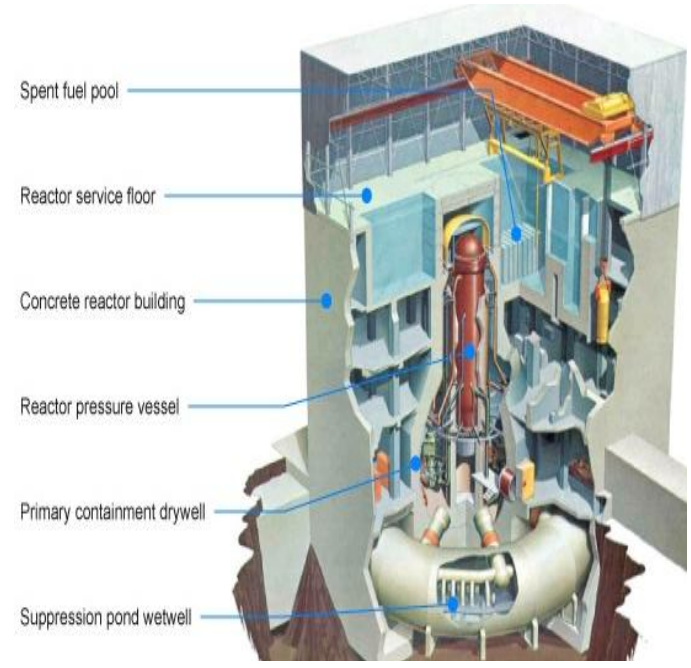

Fig. 4: BWRs supplied by GE, Toshiba \& Hitachi at Fukushima Source: Nuclear Energy Institute

It has been postulated that the reaction in reactors Unit 1,2 and 3 produced 800 to 1000 kilograms of Hydrogen gas per unit. The pressurized Hydrogen gas was vented out of the reactor pressure vessel. Thus, the Hydrogen gas got mixed with the ambient air and subsequently reached explosive concentration limits in Units 1 and 3. Moreover, piping connections between Units 3 and 4 caused passage of generated Hydrogen from Unit 3 to Unit 4. Additionally, the same dissociation reaction was occurring in the spent fuel pool (SFP) in Unit 4. Thus, Unit 4 also filled with Hydrogen, resulting in an explosion. In comparison with TMI-2 accident, in Fukushima accident, the amount of radioactivity released was higher due to Hydrogen explosion at secondary containment and suppression pool.

As a consequences of the accident, total $4,00,000$ people were evacuated; 1,60,000 people were from within $20 \mathrm{~km}$ exclusive zone. The number of deaths (around 1,700) those occurred are attributed to stress, fatigue and hardship of living as evacuees. Since the accident, the radioactive water has been flowing into the ocean. The Unit 1 at Fukushima has been discharging radioactive water at a rate of around 2 billion becquerels per day endangering aquatic life surrounding Japan and other parts.

\section{Necessity of nuclear energy and safer nuclear fuels}

According to international energy outlook, world energy consumption will grow from 524 quadrillion British unit (Btu) to 820 Btu between the years 2010 and 2040, i.e. rise of around 56\%. The top three courtiers in the coal productions are China, America and Australia. Moreover, the top three countries in the crude oil productions are Saudi Arabia, America and Russia. In 2017, the top three natural gas producers are America, Russia, Iran [12]. Envisage the combustion of natural gas, when a natural gas is combusted, pollutants such as Carbon dioxide $\left(\mathrm{CO}_{2}\right)$, Carbon monoxide (CO), nitrogen oxides (NOx), Nitrous oxide $\left(\mathrm{N}_{2} \mathrm{O}\right)$, volatile organic compounds (VOCs), particulate matter (PM), and trace amounts of Sulfur dioxide $\left(\mathrm{SO}_{2}\right)$ are released into the environment. Eventually, this will lead total estimated increase in $\mathrm{CO}_{2}$ emission by $40 \%$, thereby causing the global warming. It is true that Industrialization processes are polluting the atmosphere of the earth. Gases such as Carbon dioxide, Nitrogen dioxide etc. are causing a green house effect. As a result, global warming is taking place. Gases like Sulphur dioxide are giving rise to acid rains. Metropolitan cities are becoming a jungle of concrete; therefore there is necessity of small modular reactor for the development of isolated villages.

The process of industrialization can't be stopped because it is necessary for the development of the mankind. It is creating job opportunities for people. These jobs are necessary for their survival. If this industrialization is creating problems, remedies to these problems are necessary.

The solar and wind are unsteady and unreliable, very low energy density sources of energy, therefore they have very poor availability factor with significantly lower plant efficiencies. Also, during the rainy season, the power conversion systems have substantially reduced output with very lower efficiency. It has been investigated that the performance of vertical axis wind turbines (VAWT) is deteriorated seriously in different rain conditions [13]. According to the principle of conservation of energy, these sources of energy are incompatible for industrial load demand where 24 hours of operation is required with insufficient input energy. In many engineering applications, the amount of energy converted per unit time in Watts is significantly important.

Few light elements such as Deuterium, Tritium as well as Helium-3 are used as fusion fuel but there is no sustainable fusion reaction for more than few minutes yet. Therefore nuclear fission becomes inevitable source of clean energy.

Also, several useful scientific activities are going on at Antarctica. These places experience six months of daylight and six months of darkness. The lowest temperatures measured lies from $-92^{\circ} \mathrm{C}$ to $-98^{\circ} \mathrm{C}$. In order to continue scientific experiments at these difficult places, electricity is required which is expected to be generated from small modular nuclear reactor.

Nuclear energy is most suitable and clean source of energy. It plays vital complementary role to other low energy density sources of energy. Nuclear fuel has a high calorific value. One ton of natural uranium can produce more than 40 million kilowatthours of electricity. This energy is equivalent to about 80,000 barrels of oil or 16,000 tons of coal. Without production of carbon dioxide, advanced nuclear power plants have (20-25\%) higher efficiency than conventional plants which make use of fossil fuel. Nuclear energy is used as process heat source for industrial processes such as continuous mass production of hydrogen or extraction of bitumen from the shell.

The Nuclear Power Plants (NPPs) can supply large scale electrical power at a reasonable price as a full-time available base- 
load to electrical grids without polluting the environment. Nevertheless, safety has been a primary concern because of the potential release of radioactive materials from an accident site. Although safety precautions were implemented, there have been major accidents, such as Three Mile accident, Chernobyl accident and recent Fukushima accident. Therefore, both industry and regulators from India are re-analyzing safety aspects for NPPs and have taken number of measures to address challenges raised from these accidents.

With compare to Uranium reactors, far less radioactive waste quantities are produced by Thorium reactors and these wastes are less shorter-lived and radioactive. Therefore, nuclear fuels developed from Thorium are environmentally benign. India has one of the largest reserves for Thorium. The three stage recycling method enables development of peaceful applications from Thorium fuels.

The Atomic Energy Regulatory Board (AERB) has set new requirements to be satisfied by nuclear fuels to overcome the accident scenarios. These requirements have been satisfied by designed nuclear fuels. The design flow from mining to the testing of these safe nuclear grade fuel elements has been explained in the following sections.

\section{Uranium mining and fuel manufacturing}

In India, the mining and processing operations with Uranium ores are performed by the Uranium Corporation of India Ltd. (UCIL) as described below.

\subsection{Uranium investigations with ground survey}

Recently, reconnaissance $(5,432 \mathrm{sq} \mathrm{km})$ and detailed surveys $(282.75 \mathrm{sq} \mathrm{km})$ helped in finding the following promising Uranium anomalies of known occurrences in various geological environs:

a. Siwalik Group, Una district, Himachal Pradesh: Sandstone at Gwalsar-Parah.

b. Mahadek basin, East Khasi Hills district, Meghalaya: Sandstone at Laitduh.

c. Motur Formation, Satpura Gondwana basin, Betul district, Madhya Pradesh: Sandstone at Dharangmau.

d. Betul Crystalllne complex, chhidwara district, Madhya Pradesh: Brecciated quartz reef/ vein in granite near Bijori,Bhuli, Khudharadhana, Setparas and Sajba.

e. Rohil and its extensions, Sikar district, Rajasthan: Albitite zones in Rohil Central western extension, Gumansinghki Dhani, Narsinghpuri and Jahaz areas (Fig.5).

f. Bortalao Formation, Rajnandgaon district, Chhattisgarh: Gritty sandstone and conglomerate of Bortalao Formation along Kolarghat-Kauhapani- Gandhinagar, Bortalao-KhampuraBurhan chhapar and Nawatola-Ramatola-Kolarbhatti tracts.

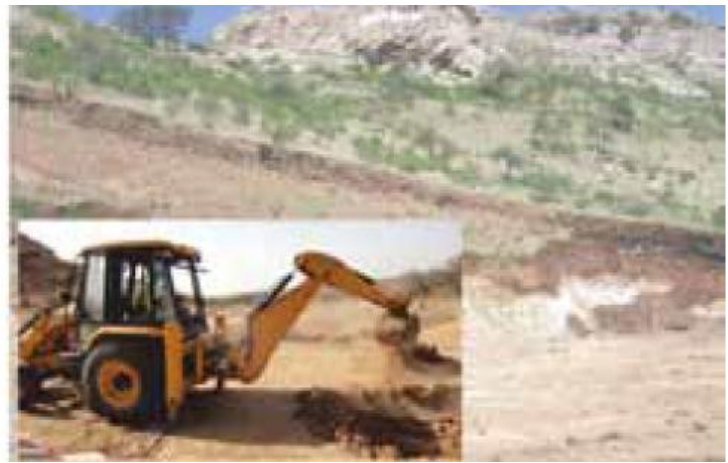

Fig. 5: Exploratory mining site at Rohil uranium deposit, Sikar district, Rajasthan [14]
The processing of geophysical data of Dungarpur Block in Aravalli Fold Belt, Rajasthan has resulted in the identification of eleven potential target zones around Undwala, East of Tartai \& Chhoti Mandli, Lasara, Bachi-fala \& Sarangi, Parsola, North of Parsola, East of Manpur, North of Bhabrana, South of Jambura, PavatiBurel and Salumber and some other sites in Madhya Pradesh (Fig.6).

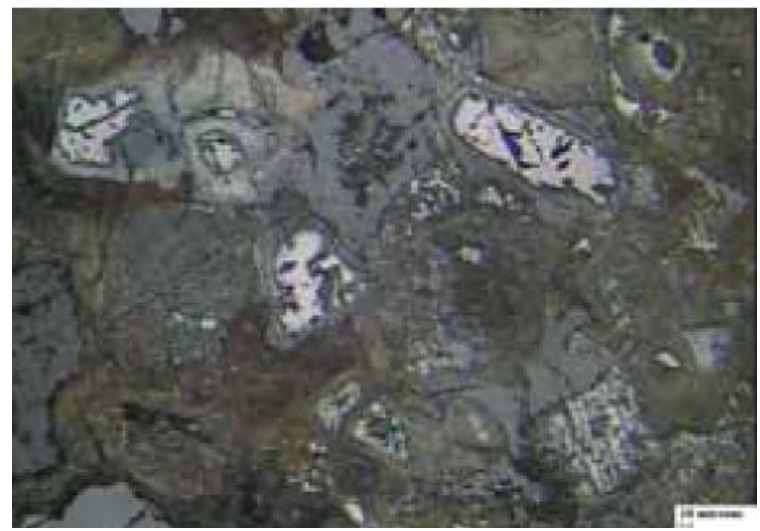

Fig.6 : Photograph showing discrete Uraninite in aernite, Dharanmau area, Betul district, Madhya Pradesh [14]

However, these Uranium resources are insufficient for growing energy demand.

\subsection{Processing of Uranium ore}

The Fig. 7 shows nuclear grade yellow cake and impure CSDU. During the processing of secondary source of U, the Crude Sodium Diuranate obtained, contains impurities such as iron (10\%) and rare earths (5\%). An extraction process selectively extracted impurities including rare earths remained in the aqueous phase while $\mathrm{U}$ into the organic phase.

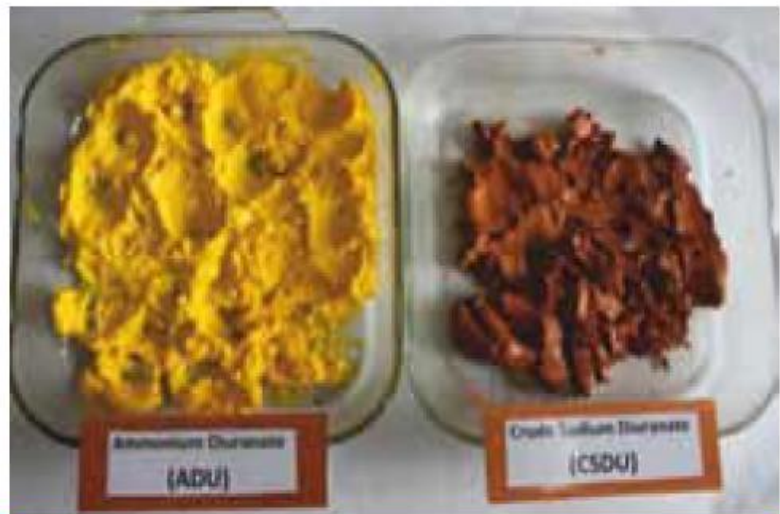

Fig. 7: The nuclear grade yellow cake and impure CSDU [14]

\subsection{Nuclear fuel manufacturing}

The Nuclear Fuel Complex (NFC), at Hyderabad, a constituent unit of Department of Atomic Energy (DAE) is engaged in the production of natural Uranium oxide fuel bundles for PHWRs, and fuels for other types of reactors, Reactor Core Structurals, Reactivity Control Mechanisms and special materials like Tantalum, Niobium etc. In addition, NFC produces fuel cladding tubes and other critical components like all the core sub-assemblies, Hexagonal wrapper tubes etc., made out of special materials e.g. stainless steels for Fast Breeder Reactors. Also, NFC has been manufacturing Stainless Steel Tubes/ Pipes, MDN-250, MDN- 350, MDN-59, SuperNi-42 tubes, Nimonic-75 tubes, and Titanium alloy products for critical application in Reprocessing Plants, Nuclear Power Plants, and Space establishments.

A rapid scanning machine for scanning the fracture or manufacturing fault in fuel elements used at NFC is shown in the Fig. 8 
This will ensure that $\mathrm{UO}_{2}$ pellets stack and fit well in fuel pins without any cracks. The machine also acts as tube feeding and butting system.

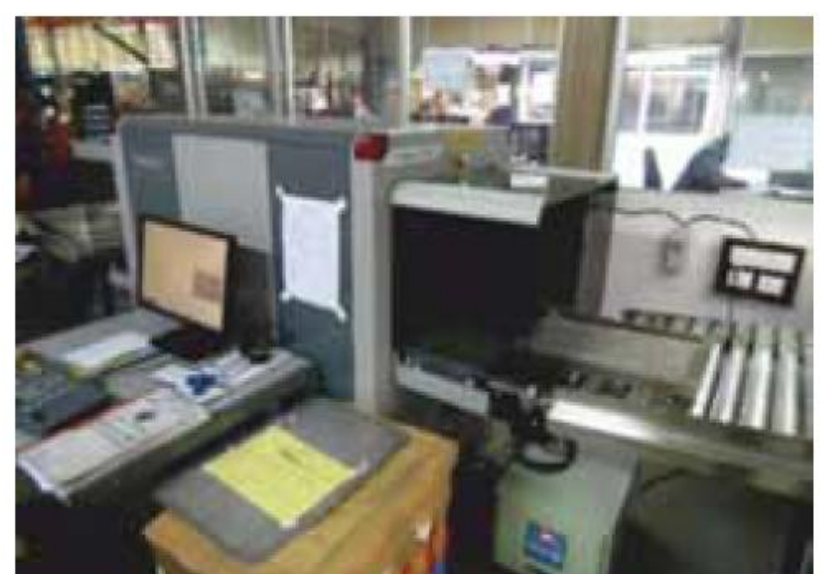

Fig. 8: Scanning of Fuel Elements [14]

NFC has successfully logged record numbers for each fuel pellets, fuel bundles which have met the safety requirement. All the indigenous raw material in the form of DU/HTUP/SU received from M/s UCIL and spent fuel from IGCAR are converted into fuel rods in order to fulfill the requirement of Out of Safeguard (OSG) reactors.

\section{Nuclear materials}

Nuclear Fuel Complex has come up with safe fuel designs which are best suited for operation during any accident scenarios. The Table 2 enlists some of the materials used in PWR cores and their corresponding cross-section in thermal energy range.

Table 2: List of some of materials used in PWR cores and their macroscopic cross-sections in thermal energy

\begin{tabular}{cccc}
\hline Material & $\sum_{\mathrm{tr}}\left(\mathrm{cm}^{-1}\right)$ & $\gamma \sum_{\mathrm{f}}\left(\mathrm{cm}^{-1}\right)$ & $\begin{array}{c}\text { Relative } \\
\text { Absorption }\end{array}$ \\
\hline $\mathrm{H}$ & $1.8 \times 10^{-2}$ & 0 & 0.053 \\
$\mathrm{O}$ & $7.15 \times 10^{-3}$ & 0 & 0.0 \\
$\mathrm{Fe}$ & $9.44 \times 10^{-4}$ & 0 & 0.026 \\
$\mathrm{U}^{235}$ & $3.05 \times 10^{-4}$ & 0.146 & 0.602 \\
$\mathrm{U}^{238}$ & $6.98 \times 10^{-3}$ & $1.19 \times 10^{-2}$ & 0.091 \\
Core & $3.62 \times 10^{-2}$ & 0.1569 & 1.000 \\
total & & & \\
\hline
\end{tabular}

\section{Illustration of some safer fuels and reactor core building blocks from NFC, Hyderabad}

The combination of nuclear fuels with different moderator materials has several advantages over conventional fuel. If $u$ is lethargy gain, then the probability for collision of a neutron for different materials is given as,

$P\left(u^{\prime} \rightarrow u\right)=\frac{e^{u^{\prime}-u}}{(1-\alpha)} \quad\left\{\begin{array}{l}\text { for } u-\ln \left(\frac{1}{\alpha}\right)<u^{\prime}<u, \\ \text { otherwise, }\end{array}\right.$

where $\alpha$ is defined as $\frac{(\mathrm{A}-1)^{2}}{(\mathrm{~A}+1)^{2}}$. Therefore average gain in the lethargy $(\overline{\Delta u})$ is given as,

$$
\overline{\Delta u}=\int_{\alpha E_{i}}^{E_{i}} \Delta u \quad P\left(u^{\prime} \rightarrow u\right) d u^{\prime} .
$$

The effect of different moderators such as $\mathrm{Be}^{9}$, $\mathrm{C}^{12}, \mathrm{Na}^{23}, \mathrm{~Pb}^{207}, \mathrm{Th}^{232}, \mathrm{U}^{238}$ with nuclear fuels have been studied while making the reactor core critical. The number of collisions required to thermalise a neutron from $2 \mathrm{MeV}$ to $1 \mathrm{keV}$ in these moderator materials have been plotted in the Fig. 9. Thus, the number of collisions required to reduce the neutron energy from 2 $\mathrm{MeV}$ to $1 \mathrm{keV}$ increases linearly with atomic massA.

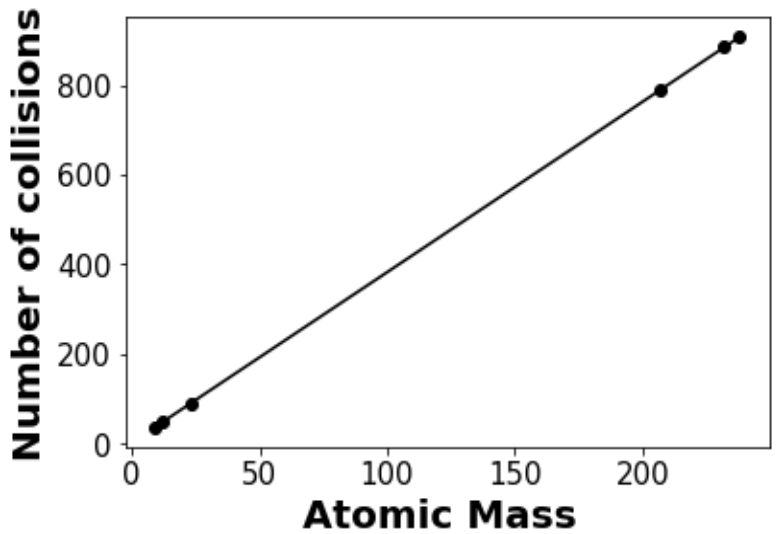

Fig. 9: Number of collisions necessary to slow down neutron from $2 \mathrm{MeV}$ to $1 \mathrm{keV}$ energy

The interaction rate of neutrons with atoms of material having mass number $\mathrm{A}$ is denoted with $\mathrm{F}$. The first order collision density $\left(F_{1}\right)$ denotes the collision density that all the source neutrons need one collision to reach $\mathrm{dE} ; \mathrm{F}_{2}$ indicates collision density that all the neutrons need two collision to reach $\mathrm{dE}$ and so on (Fig.10). If neutron source of strength $S_{0}$ emits neutrons of energy $E_{0}$, the expressions for $\mathrm{F}_{1}$ and $\mathrm{F}_{2}$ are given below:

$$
\begin{aligned}
\mathrm{F}_{1} & =\frac{S_{0}}{\mathrm{E}_{0}(1-\alpha)} \text { for } \alpha \mathrm{E}_{0}<\mathrm{E}<\mathrm{E}_{0}, \\
& =0 \text { for } \mathrm{E}<\alpha \mathrm{E}_{0} . \\
\mathrm{F}_{2} & =\frac{S_{0}}{\mathrm{E}_{0}(1-\alpha)^{2}} \ln \left(\frac{\mathrm{E}_{0}}{\mathrm{E}}\right) \text { for } \alpha \mathrm{E}_{0}<\mathrm{E}<\mathrm{E}_{0}, \\
& =\frac{S_{0}}{\mathrm{E}_{0}(1-\alpha)^{2}} \ln \left(\frac{\mathrm{E}}{\alpha^{2} \mathrm{E}_{0}}\right) \text { for } \alpha^{2} \mathrm{E}_{0}<\mathrm{E}<\alpha \mathrm{E}_{0},
\end{aligned}
$$

where as $\mathrm{F}_{3}$ is obtained from $\mathrm{F}_{2}$ and the expressions for third order collision density $\left(F_{3}\right)$ is given below:

$$
\begin{gathered}
\mathrm{F}_{3}=\frac{\mathrm{S}_{0}}{2 \mathrm{E}_{0}(1-\alpha)^{3}} \ln ^{2}\left(\frac{\mathrm{E}}{\mathrm{E}_{0}}\right) \text { for } \alpha \mathrm{E}_{0}<\mathrm{E}<\mathrm{E}_{0}, \\
=\frac{\mathrm{S}_{0}}{\mathrm{E}_{0}(1-\alpha)^{2}}\left\{\ln \left(\frac{\mathrm{E}_{0}}{\mathrm{E}}\right) \ln \left(\frac{\mathrm{E}}{\alpha^{2} \mathrm{E}_{0}}\right)+\ln \left(\frac{\alpha \mathrm{E}_{0}}{\mathrm{E}}\right) \ln \left(\frac{\mathrm{E}}{\alpha^{3} \mathrm{E}_{0}}\right)\right\} \\
\text { for } \alpha^{2} \mathrm{E}_{0}<\mathrm{E}<\alpha \mathrm{E}_{0},
\end{gathered}
$$

also,

$$
F_{3}=\frac{S_{0}}{2 E_{0}(1-\alpha)^{3}}\left\{\ln ^{2}\left(\frac{E}{\alpha^{3} E_{0}}\right)\right\} \text { for } \alpha^{3} E_{0}<E<\alpha^{2} E_{0} \text {. }
$$

When $\mathrm{E}>\alpha^{3} \mathrm{E}_{0}$, in asymptotic energy region, the collision density function $F$ becomes smoother and attains the value $\frac{S}{\overline{\Delta \mathrm{uE}}}$. The Fig. 10 shows, the first, second and third order neutron collision densities for unit source of $2 \mathrm{MeV}$ neutrons in $\mathrm{Th}^{232}$.

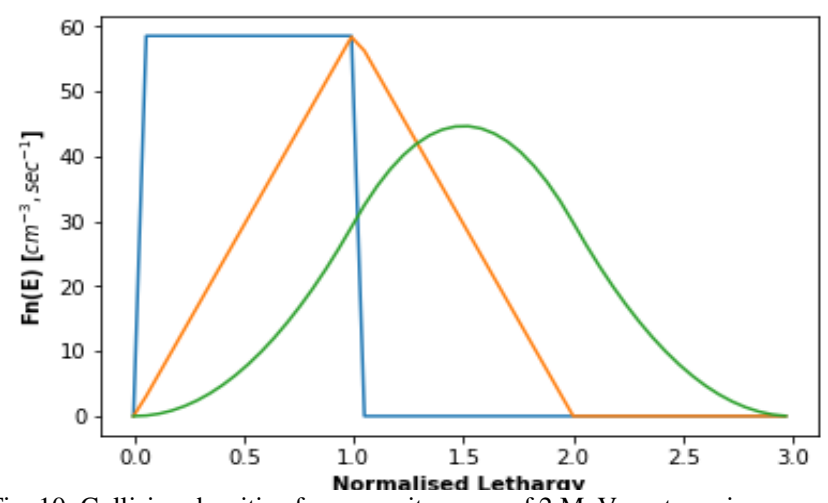

Fig. 10: Collision densities for one unit source of $2 \mathrm{MeV}$ neutrons in $\mathrm{Th}^{232}$. 
Several eutectics which are mixture of different moderator materials have been developed at BARC.

The cross-section library database from Nuclear Data Physics Centre of India (NDPCI) at Bhabha Atomic Research Centre (BARC) has been used to find out criticality parameters for the reactors. The study has revealed that the compound nucleus formation and neutron production time is approximately $10^{-22}$ seconds for different nuclear reactions. The neutron clock has been used to determine pre-fission time from measured prefission neutron multiplicity values. The compound nuclear formation time is determined by measurements of pre-fission multiplicity for two different entrance channel forming the same compound nucleus $\mathrm{C}_{\mathrm{f}}^{248}$ having different entrance channel dynamics [15].

As the capture cross-section is high in resonance energy range, moderators such as $\mathrm{U}^{238}, \mathrm{Th}^{232}$ upon capture of neutrons are converted into fissile material, thus breeding of new fuel takes place. The NFC has been manufacturing different types of fuels with different shapes for the safe operation of fuel even during the accident scenarios. The stress tests performed on nuclear fuels (Fig. 11 - Fig.17) guarantees that there will not be any mechanical failures during severe accidents.

For high temperature reactor operation $\left(\mathrm{T}_{\mathrm{c}} \sim 1000^{\circ} \mathrm{C}\right)$, the BISO (Bi-stuctural isotropic) or TRISO (Tri-stuctural isotropic) fuel elements are embedded inside either the fuel compacts or pebbles (Fig. 11, Fig.12). In TRISO particles, the fuel kernel $\left(\mathrm{UC}_{2}+\mathrm{ThC}_{2}\right)$ is surrounded by three high density carbon layers following low density pyrolyticcarbon (Fig. 11 and Fig.12). Although, TRISO coated particle fuel can withstand in the very high temperature environment of $1600^{\circ} \mathrm{C}$ without failure, a hightemperature gas-cooled reactor (HTGR) at Fort St. Vrain in United States is permanently shut down due to electrical, corrosion, and many other issues within few years. The Innovative High Temperature Reactor (IHTR), overcomes water infiltration as well corrosion issues at high temperature conditions. The IHTR-A makes use of fuel in the form of pebbles in which TRISO particles are embedded inside Pebbles. According to crystallographic analysis, the average void fraction among the pebbles to attain the criticality is 0.4. For High Temperature Reactor operation, the TRISO particles can be also embedded inside the fuels illustrated in the Fig. 13 to Fig. 16.Ceramic material have been selected for the construction of reactor core.

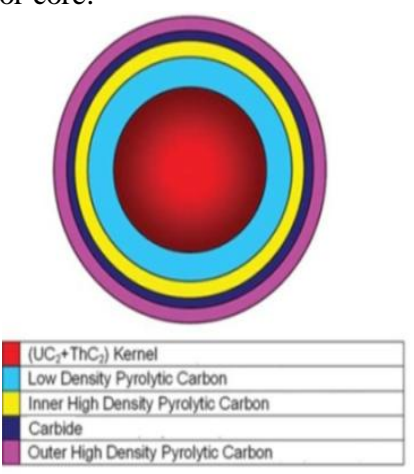

Fig. 11:Tristructural-isotropic (TRISO) particle element

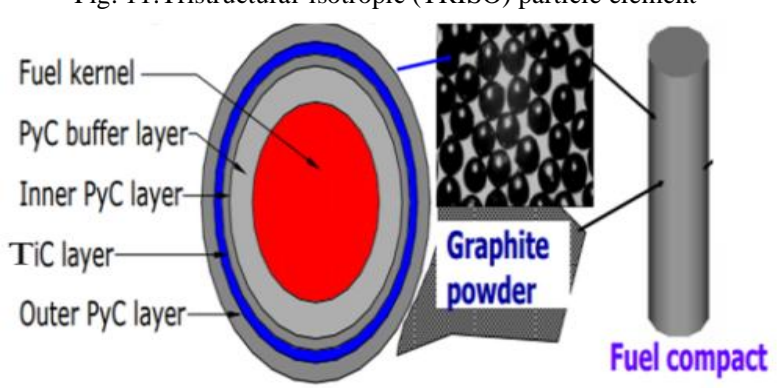

Fig. 12: Spherical TRISO particles inside fuel compact or pebbles

The functions of TiC interlayer in spherical TRISO is described

below:

The TiC interlayer is used to retain all the gaseous fission products released from the kernel hence, it functions as a pressure vessel. Moreover, TiC also functions as a diffusion barrier for metallic fission products.

For low temperature reactor operation fuel pellets are used (Fig.13-Fig.17) without TRISO particles. For low temperature reactor fuel, the $\mathrm{UO}_{2}$ powdered fuels are sintered and stacked inside fuel package. The fuel pins (Fig.13-Fig.17) inserted into the fuel block, are directly or indirectly cooled through a moderator.

The American reactor CP (Chicago Pile) makes use of nuclear fuel somewhat similar to fuel shown in the Fig.15, however, could not be run successfully for prolonged operation. The fuel in Fig. 15 has unique construction. The first research reactor in Asia (Apsara) became operational in Bhabha Atomic Research Centre in August 1956. The reactor was decommissioned in 2009, after providing more than five decades of dedicated service to the researchers. A swimming pool type research reactor "Apsaraupgraded", of higher capacity was born on 10th September 2018 at 18:41 hrs, sixty-two years after Apsara came into existence. The indigenously developed reactor uses plate type dispersion fuel elements made up of Low Enriched Uranium (LEU)

The annular fuels shown in Fig. 16.a and Fig. 16.b can be directly or indirectly cooled through moderators available. The Annular Fuels (Type 1) have multiple moderator rings around the central region like spherical TRISO particle for safety purpose (Fig.17). Like TRISO fuel described earlier, the annular fuels have superior proliferation resistance attributes. The high temperature and neutron fluence grade cladding material acts as fission barrier. Nuclear fuels (Fig. 12-Fig.18) are manufactured at Nuclear Fuel Complex, Hyderabad considering all the other safety perspectives. Due to large heat transfer surface area, the fuel temperatures are dropped substantially. This reduces Hydrogen generation and reactor core melt risks in case of accident scenarios.

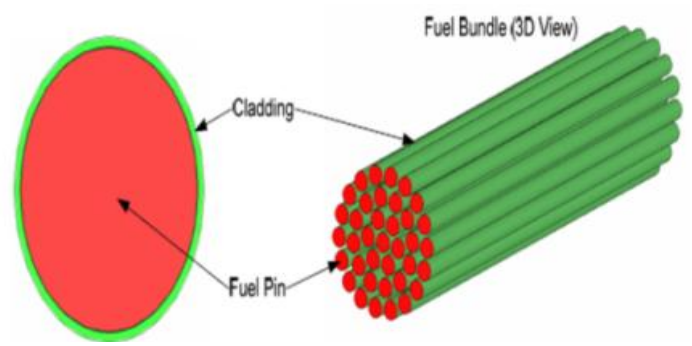

Fig. 13: Fuel pins.

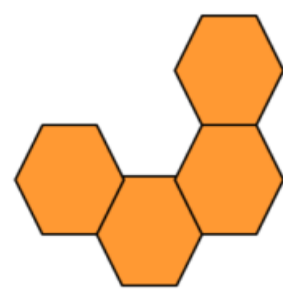

Fig. 14.a:Hexagonal fuel cluster

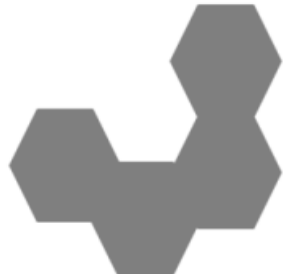

Fig. 14.b:Hexagonal moderator cluster

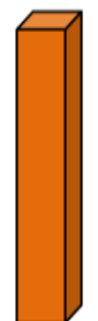

Fig. 15: Fuel stick used in the plate type fuel. 

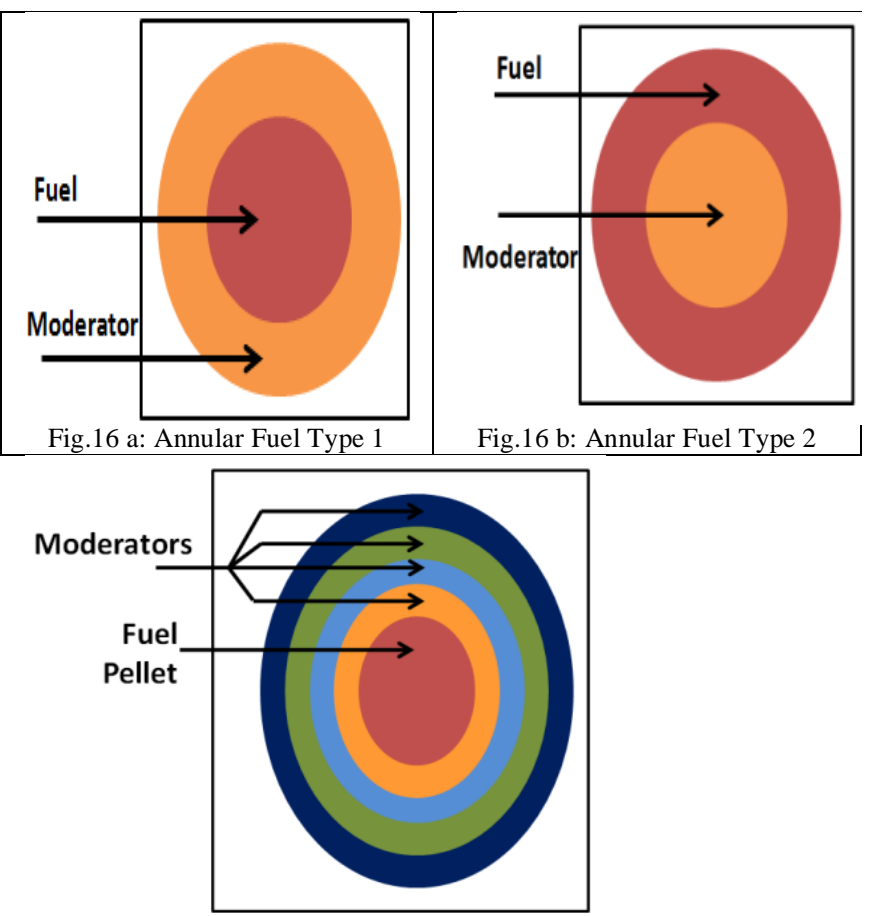

Fig.17: Annular Fuel Subtype 1

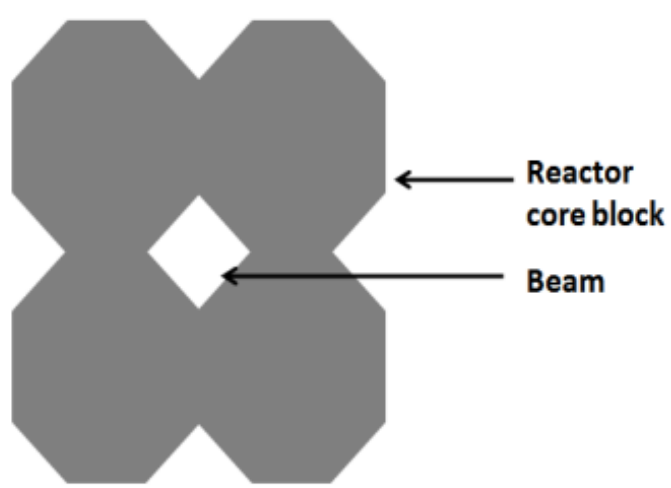

Fig. 18: Lattice for reactor core

Some of the functional requirements that have been established by these reactor fuels are described below:

1. At BARC nuclear fuels have been developed with various interlayers e.g. TiN, $\mathrm{TiC}, \mathrm{ZrC}$, etc. to prevent potential release of radioactive materials. These safe fuels are capable to generate the required power with negative fuel temperature coefficient for the required exit burn-up.

2. The developed fuel retains all types of fission products; therefore there is no leakage or release of radioactive materials into the primary coolant.

3. The developed fuels help in minimizing parasitic neutron capture.

4. The fuel tube and fuel compact locations are maintained in the core, thus basic nuclear and thermal-hydraulic requirements are satisfied (Fig.19).

5. The fuel tube directs reactor coolant through the core to the outlet with required flow distribution so that the heat transfer performance requirements are met during all modes of reactor operation or transient.

6 . The core structural oppose material damage caused by irradiation-induced effects.

7. During the anticipated operational occurrences or normal operation, the mechanical design of fuel assures that fuel damage is improbable.
8. Safe handling, shipping, as well as core loading of the fuel is possible.

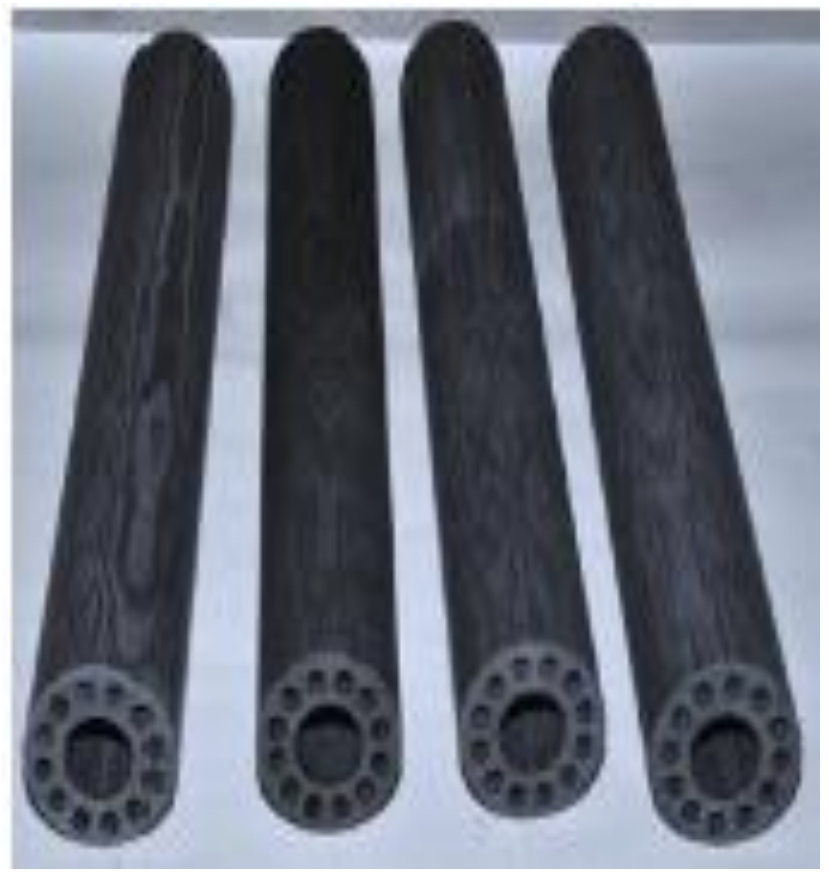

Fig. 19: Composite material tubes.

It has been experimentally found that reactor fuels in the form of $\mathrm{U}_{3} \mathrm{Si}_{2}$ and $\mathrm{UN}-\mathrm{U}_{3} \mathrm{Si}_{2}$ have higher thermal conductivity than that of fuels in the form of $\mathrm{UO}_{2}$ and $\mathrm{UO}_{2}-\mathrm{BeO}$. Fuels in the form of $\mathrm{UN}$ have higher thermal conductivity and uranium density thus promising candidate for chain reaction, nonetheless it is susceptible corrosion and oxidation.

Table 3: Parameters of Some of Fuel Compositions

\begin{tabular}{lcccc}
\hline Parameter & $\mathrm{UO}_{2}$ & $\begin{array}{c}\mathrm{UO}_{2}-\mathrm{BeO} \\
(10 \% \mathrm{vol} \mathrm{Be} 0)\end{array}$ & $\mathrm{U}_{3} \mathrm{Si}_{2}$ & $\begin{array}{c}\mathrm{UN}-\mathrm{U}_{3} \mathrm{Si}_{2} \\
\left(30 \% \mathrm{vol}_{3} \mathrm{Si}_{2}\right)\end{array}$ \\
\hline $\begin{array}{l}\text { Fracture Stress [MPa] } \\
\text { Linear Thermal }\end{array}$ & $\begin{array}{c}\sim 105 \\
\left.\text { Expansion [K } \mathrm{K}^{-1}\right]\end{array}$ & $\begin{array}{c}\sim 105 \\
1.05 \times 10^{-5}\end{array}$ & $\begin{array}{c}\sim 05 \times 10^{-5} \\
250\end{array}$ & $\begin{array}{c}9.38 \times 10^{-6} \\
1.53 \times 10^{-5}\end{array}$ \\
$\begin{array}{l}\text { Thermal Conductivity } \\
{\left[\mathrm{Wm}^{-1} \mathrm{~K}^{-1} \text { ] }\right.}\end{array}$ & 3.55 & $\sim 5.58$ & 14.98 & $\sim 19.18$ \\
Metal Density & 9.66 & 8.74 & 11.30 & 12.92 \\
Theoretical Density & 10.95 & 10.08 & 12.25 & 13.66 \\
Elastic Modulus[GPa] & $\sim 204$ & $\sim 205$ & $\sim 118$ & $\sim 262$ \\
Specific Heat[Jkg $\left.{ }^{-1} \mathrm{~K}^{-1}\right]$ & 245 & 245 & 208 & 206 \\
Melting & $\sim 2800$ & $\sim 2800$ & $\sim 1665$ & $\sim 2800$ \\
Temperatures $\left[{ }^{\circ} \mathrm{C}\right]$ & & & & \\
\hline
\end{tabular}

Therefore, fuels in the form of $\mathrm{UN}-\mathrm{U}_{3} \mathrm{Si}_{2}$ were developed to overcome the issue of corrosion and oxidation. By comparing various parameters in Table 3 for various types of fuels it can be deduced that $\mathrm{UN}-\mathrm{U}_{3} \mathrm{Si}_{2}$ fuels have the most desired thermo-physical properties among four fuel compositions.

In order to reduce fission gas release, fuel temperature \& $\mathrm{SiC}$ cladding failure risk, $\mathrm{UN}-\mathrm{U}_{3} \mathrm{Si}_{2}$ fuel was found to be the best choice.

An effective approach to reduce stress-induced failure risk, the fuel temperature, pellet-clad mechanical interaction and fssion gas release is to increase the fuel thermal conductivity.

UN fuels have a lower creep rate, higher fracture stress \& higher modulus, as a consequence nitride fuel is vulnerable to Pellet-Clad Mechanical Interaction (PCMI) induced failure and cracking which can lead to severe issues as depicted in the Fig. 20. 


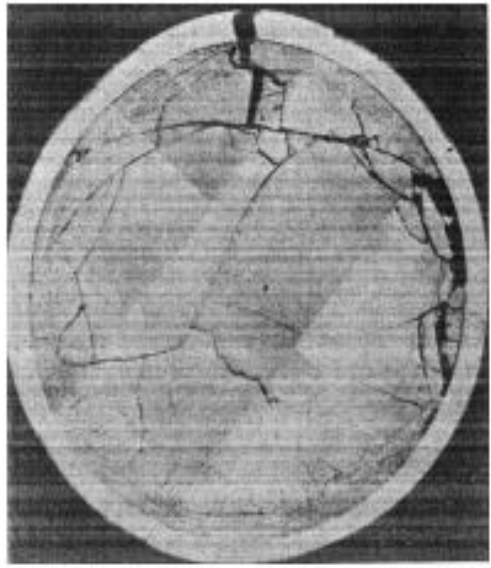

Fig. 20: Horizontal cross section of (Pu, UN) fuel pellet having axial temperature of $1090^{\circ} \mathrm{C}$.

This type of problem is handled by the reduction in UN fuel density to $80-85 \%$ of the theoretical density. Similarly, the density reduction was considered for $\mathrm{UN}-\mathrm{U}_{3} \mathrm{Si}_{2}$ fuel to avoid PCMI-induced failure and cracking.

Reducing the fuel temperature and fission gas release by using annular fuels (Fig. 16.b) is interesting solution which has been investigated by K.Umasankari, P. Vijayan et. al [16]. The silicon carbide $(\mathrm{SiC})$ has good performance with regard to oxidation resistance, neutron economics and irradiation stability for accident tolerant fuel cladding. The loss of the tubing hermeticity and cracking of the $\mathrm{SiC}$ matrix caused by the brittle nature of the $\mathrm{SiC}$ puts limit on engineering application of $\mathrm{SiC}$ cladding. Therefore, additionally, $\mathrm{TiC}$ and $\mathrm{TiN}$ are invented and selected as alternative cladding material.

In order to prevent worst case partial core melt scenario (e.g. that of for PWR in TMI-2) with Hydrogen generation reaction, annular fuel with multi-layered coating has been invented (Fig.17).

The innovative GEN IV reactors developed in India, make use of the fuel elements shown earlier (Fig. 11-Fig.17) for different reactors for a range of reactor power levels. These reactors have several unique features e.g. advance recirculation buoyancy pump systems $[17,18]$. Thus core melt risks are reduced drastically.

The low temperature reactor core compatible nuclear fuels (described earlier in Fig.13 to Fig.17) have larger heat transfer area. These fuels have higher values of equivalent hydraulic diameters which enables better heat transfer with the coolant Thereby these fuels have substantially lower temperatures in the reactor core even during accident scenarios such as loss of coolant accident (LOCA). This eliminates Hydrogen production and core melt possibilities in the reactor core in case of accidental scenarios.

\section{Coolant choice}

The coolants that can be used to remove the heat from inside the reactor core must have the following good characteristics:

1. It should perform cooling operation in the operating temperature range.

2. It should have radiolytic stability in a high radiation environment (for primary coolant only). The coolant should have a low freezing temperature, preferably lower than $525^{\circ} \mathrm{C}$ for metal coolant.

3. The coolant should have large sufficient thermal inertia and thermal conductivity.

4. It should have low vapor pressures (substantially less than one atmosphere) at operating temperatures, thus not volatile.
The molten salts seem to be excellent candidates which satisfy most of these requirements. There is no single molten salt which satisfies the requirement of low melting temperature; therefore multi-component eutectic mixtures are needed. There are some multi-component eutectic salt mixtures that satisfy the criteria of melting temperatures less than $500^{\circ} \mathrm{C}$. The multi-component mixtures usage ensures compositional and phase stability.

Some of the coolants that have been used earlier are enlisted here e.g. Helium, Nitrogen, $\mathrm{CO}_{2}$, Air, Light water, Heavy water, $\mathrm{ZrH}$, Sodium, Lead Eutectics, LiF-NaF-RbF, LiF-NaF$\mathrm{BeF}_{2}, \mathrm{NaF}-\mathrm{BeF}_{2}, \mathrm{LiF}-\mathrm{RbF}, 2 \mathrm{LiF}-\mathrm{BeF}_{2}, \mathrm{LiF}-\mathrm{NaF}-\mathrm{ZrF}_{4}, \mathrm{LiF}-$ $\mathrm{BeF}_{2}-\mathrm{ZrF}_{4}, \mathrm{LiF}-\mathrm{NaF}-\mathrm{KF}, \mathrm{NaF}-\mathrm{ZrF}_{4}, \mathrm{LiF}-\mathrm{ZrF}_{4}, \mathrm{KF}-\mathrm{ZrF}_{4}, \mathrm{RbF}-$ $\mathrm{ZrF}_{4}$.

\section{Application of Safer Fuels for Innovative Reactors}

GEN IV reactors are being developed internationally with inherent safety features. This section briefly outlines the innovative Indian GEN IV reactors which make use of invented safer nuclear fuels (described in the Section 6).

\subsection{High Temperature Gas Cooled Reactors}

The Very High Temperature Reactors (VHTRs), are being developed as a part of Gen-IV reactors (3rd stage of Indian Nuclear Program). This VHTR is also called high temperature gas cooled reactor (HTGR), which is cooled with Helium gas. This graphite moderated thermal neutron spectrum reactor is designed with the goal of higher coolant outlet temperature so as to support high temperature chemical processes such as the production of Hydrogen with thermo-chemical processes. The VHTR enables the cogeneration of electricity and process heat. Using the process heat from reactor, the Hydrogen production plant, as well as other industrial process heat applications can be built up. The VHTR produces Hydrogen from water by using electro-chemical, thermochemical or hybrid processes.

The Innovative High Temperature Reactors (IHTR A, B \& C) are thermal power reactors set to a level (about $600 \mathrm{MWt}$ ) that allows removal of decay heat by no external means. Generally, high temperature reactors make use inert Helium as coolant and graphite as moderator. However, Indian designs differ especially with regard to coolant, fuel as well as moderator. In IHTR, the emphasis has been given to advance recirculation buoyancy pumping system leading to use of lead eutectic alloy and molten salt based coolants.

Several Hydrogen production cycles are envisaged for sustainable Hydrogen production. The different Hydrogen production processes, require heat at different temperatures $823 \mathrm{~K}$ (for Copper-Chlorine process) and greater than $1123 \mathrm{~K}$ (for Sulfur-Iodine process). A decision has been taken to accomplish Hydrogen production at higher temperature with reactors operating at $1273 \mathrm{~K}$. The efficacy of IHTR to operate higher temperature facilitates Hydrogen production with higher efficiencies. The higher operating temperature of the IHTR is also well suited for electricity generation with high efficiency. For the electricity generation with high efficiency, the development of the Brayton cycle with $\mathrm{CO}_{2}$ has been in progress.

A modified pebble bed advanced high temperature reactor modeled at Ohio State University by Thomas has coolant flow upward and pebble flow in opposite (downward) direction from top to bottom [19].

The TRISO \& multi layered annular fuel elements in Fig. 11, Fig. 12 \& Fig. 17 are suitable in very high temperature reactor cores.

The Innovative High Temperature Reactor (IHTR-A) makes use of fuel in the form of pebbles in which TRISO particles 
are embedded inside. The continuous refuelling is one of the advantages for IHTR-A (Fig.21).

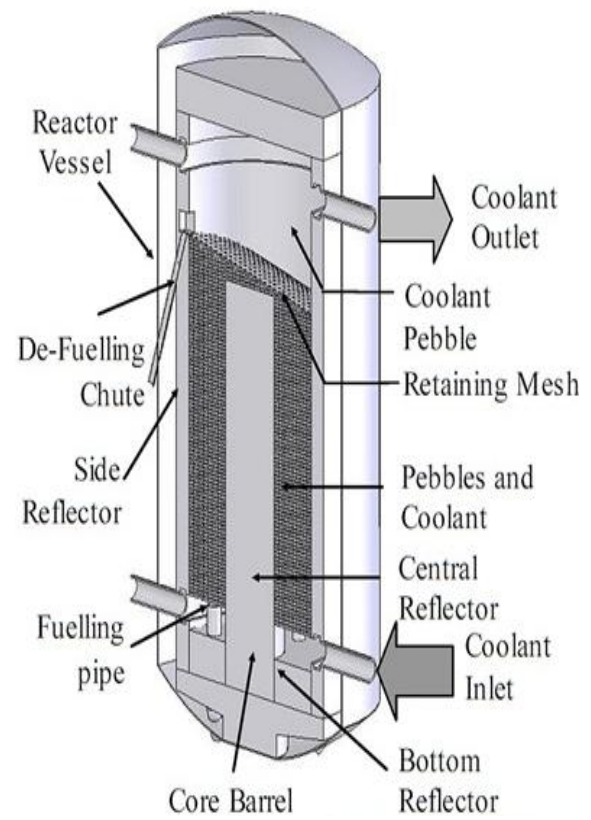

Fig. 21: Innovative High Temperature Reactor (IHTR-A) [20]

An accident scenario that models intentional withdrawal of the control rods, thereby increasing the reactor power, fuel and coolant temperature have been shown in Fig.22 and Fig. 23.Due to negative Temperature Coefficient of Reactivity, the reactor power settles down (Fig.22) after 300 seconds. The worst case fuel temperature for TRISO particle fuel in high temperature environment for this accident scenario is less than $1300^{\circ} \mathrm{C}$ (Fig.22, Fig. 23).

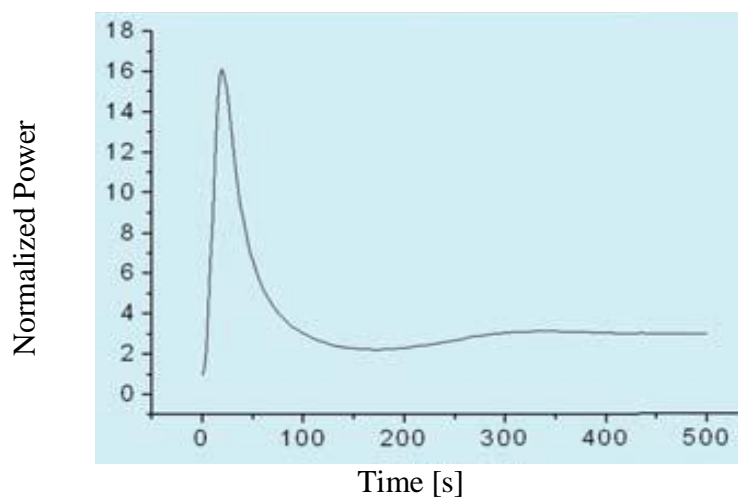

Fig. 22: Normalized Reactor Power [21]

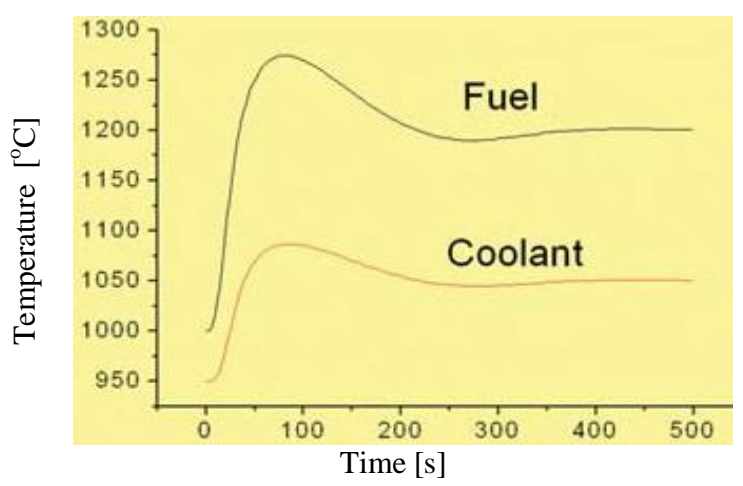

Fig. 23: TRISO fuel temperature in accident scenario [21]

IHTR-B \& IHTR-C are types of High Temperature Reactor with stationary fuel (Fig.24 and Fig. 25).
The IHTR-B makes use stationary fuel in the form of hexagonal blocks (Fig. 24). The higher reactor operating temperature of the Innovative High Temperature Reactor (IHTR) is useful in industrial applications such as Iron processing, Hydrogen productions, etc [22].

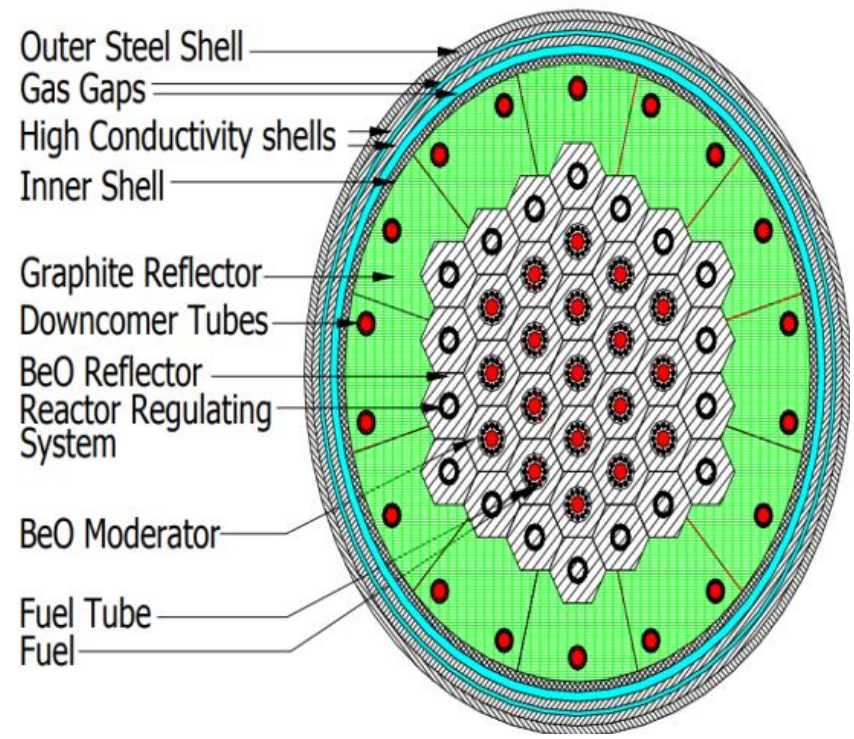

Fig.24: Innovative High Temperature Reactor (IHTR-B)

Fig. 25 shows Geometry and tracking (GEANT) model for IHTR-C with stationary fuel blocks.

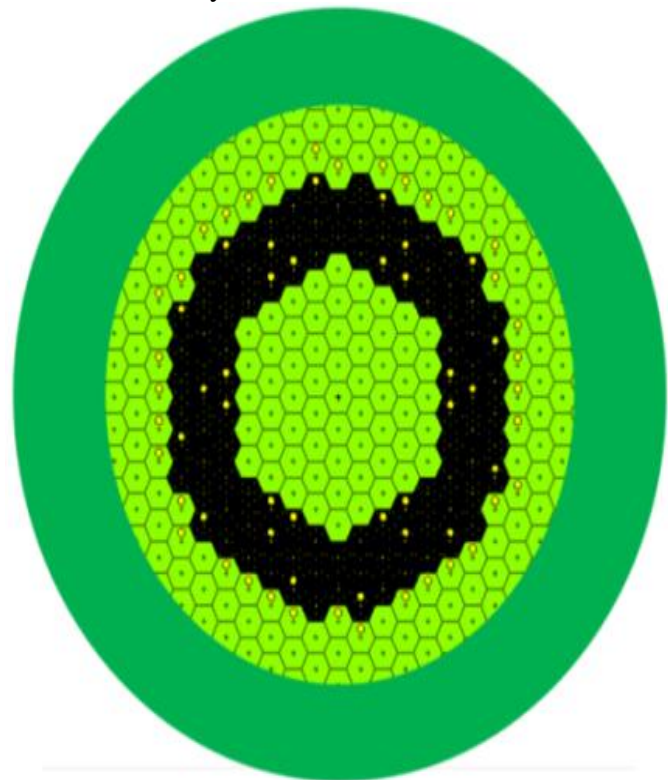

Fig 25: Innovative High Temperature Reactor (IHTR-C) with multilayered annular fuels.

\subsection{Molten Salt Breeder Reactors}

There has been great interest in the development of fuels in liquid form for Innovative Molten Salt Breeder Reactor (IMSBR). An experimental facility (Fig. 26) for molten salt reactors is developed at BARC.

The Innovative Molten Salt Reactor (IMSBR) developed at BARC makes use of proliferation resistant $\mathrm{Th}^{232}$ fuel, closing the $\mathrm{U}^{233}$ cycle. Earlier investigation on the coolant for IMSBR accomplished during the 1970 s included preparation of pure $\mathrm{LiF}_{4}$ and $\mathrm{ThF}_{4}$ including the development of equipment, solubility of PuF3 in $\mathrm{LiF}-\mathrm{BeF}_{2}-\mathrm{ThF}_{4}$ mixtures, vapour pressure determination of 
materials of interest as well as thermodynamics of $\mathrm{U}-\mathrm{Bi}$ alloys for IMSBR [23].

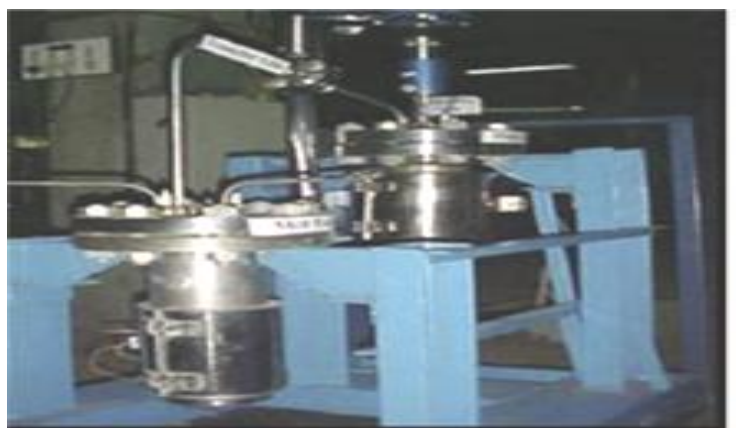

Fig. 26: An apparatus for testing molten salts (mini reactor).

\subsection{Sodium Cooled Fast Reactors}

India has been operating Sodium cooled fast reactor since several decades without any incidence. These reactors make use of fast neutron energy spectrum to cause the fission. In these reactors Sodium is used as coolant thus utmost importance is given to safety to operate such reactors. Breeder reactors EBR-1 \& Fermi were respectively shutdown due to partial meltdown in 1955 \& 1966 [24]. The development of Innovative Sodium Fast Reactors has been explained in more details in the Section 10.

\subsection{Lead Cooled Fast Reactors}

Sodium being extremely violent, the Lead has been used as Substitute coolant for fast reactor. The coolant Lead has very high melting point $(601 \mathrm{~K})$ which lead to solidification problems when reactor is operated at low temperatures. With compare to Sodium, Lead is more corrosive to steel, hence Gas Cooled Fast Reactors have been devised.

\subsection{Gas cooled high temperature fast reactor}

Fig. 27 shows cross section for High Temperature Gas Cooled Fast Reactor core. Coolant such as $\mathrm{CO}_{2}$ and Helium are under consideration.

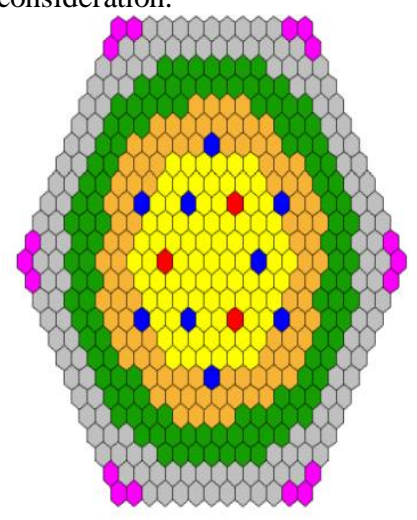

Overview of $\mathrm{CO}_{2}$ cooled high temperature fast core.

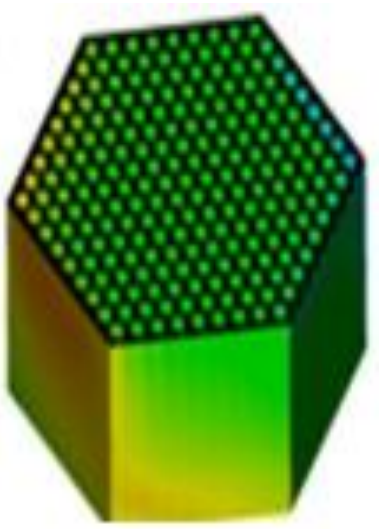

3D model for fuel block

Fig.27: Gas cooled high temperature fast reactor

The higher coolant temperature $\left(\approx 1000^{\circ} \mathrm{C}\right)$ along with Braytons cycle provide $\approx 55 \%$ efficiency.

\subsection{Accelerator driven system}

Parallel to sodium cooled reactors, in the second stage, accelerator-driven systems (ADS) have been developed to burn Plutonium and minor actinides. The accelerator driven system developed by BARC makes use of Thorium fuel inside the subcritical core of ADS which is bombarded by neutrons from spallation source. Thus, ADS help in establishing and expediting equilibrium fuel cycles for third stage nuclear power plants. It also helps in burning the nuclear waste from $3^{\text {rd }}$ stage of nuclear power plants.

\subsection{Candle type reactor}

In this reactor design, from one end of the reactor, the fission reaction zone moves to the other end with a constant velocity. The movable beam moves the neuron source axially.

Fig. 28 shows fissile reaction zone that passes through the remaining part of the reactor core axially. Once the fuel is loaded, the burn-up wave travels from one end to another end with the time span of 40-50 years. This reactor is also known as travelling wave reactor.

Candle type reactor make use of $\mathrm{U}^{233}$ and $\mathrm{Pu}^{239}$ fuels. Additionally, efforts have been pursued to integrate good properties of multilayered annular fuel with candle light reactor. Long-life CANDLE reactors with thorium fuel has been investigated for the burn-up performances and the following observations are noted.

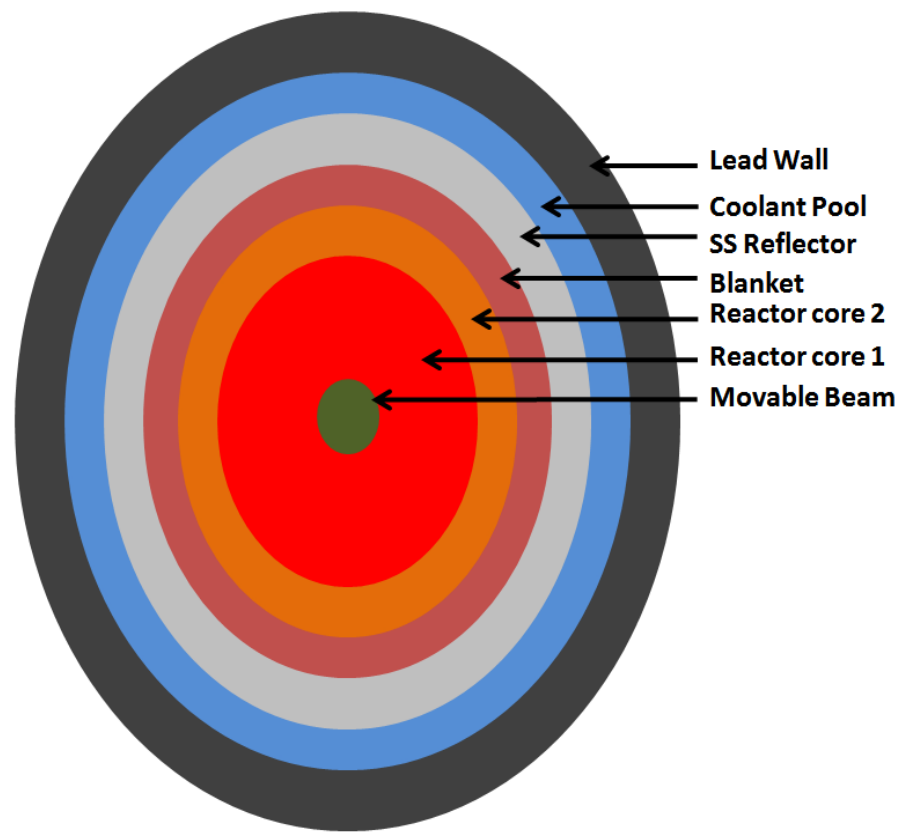

Fig. 28 : Candle type reactor

This type of reactors with thorium fuel have a higher burn-up levels about $100 \mathrm{GWD} /$ ton-HM. CANDLE reactors with thorium require about $10 \%$ enrichment.

Thus, thorium fueled CANDLE reactors are promising candidates for longer reactor operations with higher burn up performance. They are also employable for generation of electricity on external planet.

\section{Stable nuclear plant operation}

For the stable, smoother and safer operation of the overall plant, here the workings of some of systems have been briefed.

\subsection{Axial profile index}

During the reactor operation, several types of fission products are generated inside the reactor fuels which act as poison for the neutrons. These fission products imbalances the neutrons flux spatially. Subsequently, the disturbed neutron flux can create a hot spot at a particular position in the reactor core. This can raise the fuel temperature beyond the safety limit and cause partial core melt. Fig. 29 shows the build-up of normalized Xenon and Iodine 
concentration in the upper half of the reactor core on the $\mathrm{X}$ and $\mathrm{Y}$ axis respectively whereas $\mathrm{Z}$-axis indicates time in hours.

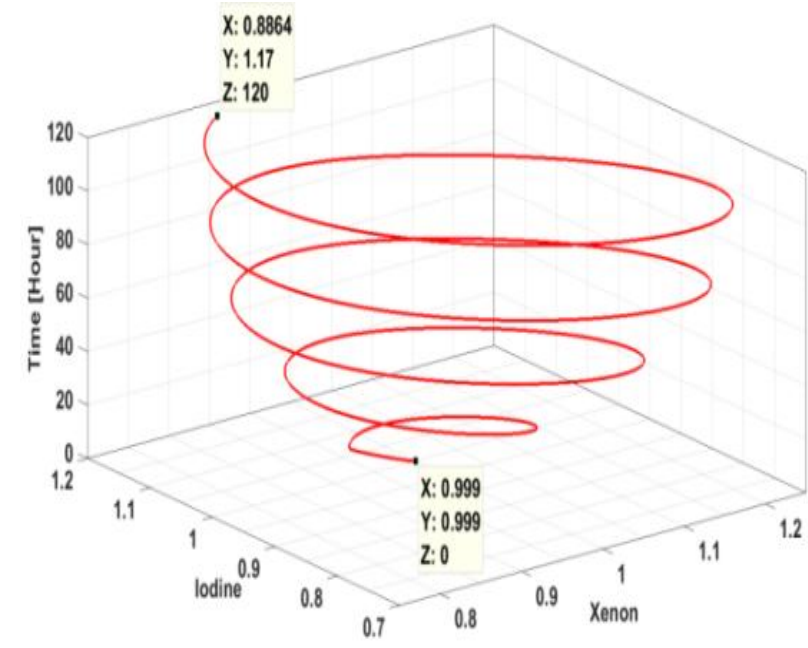

Fig.29: Growing oscillations of Xenon and Iodine

Therefore for sustained and stable operation of the reactor core, an Intelligent Constrained Receding-Horizon Predictive Control (ICRHPC) has been developed that balances the neutron flux spatially.

The growing neutron oscillations are intentionally generated at 30 Hours and killed at 60 Hours (Fig.30) by using ICRHPC.

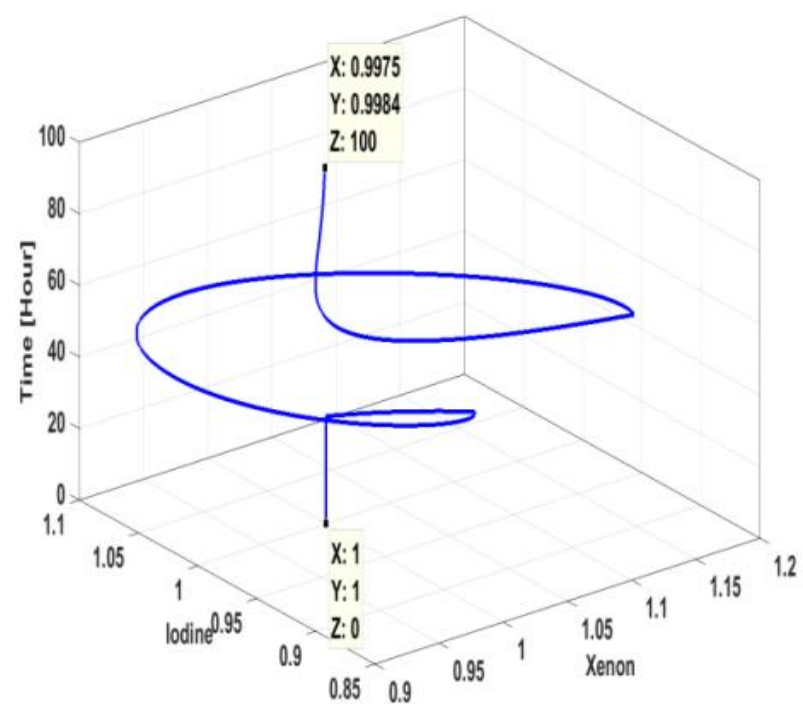

Fig.30: Phase diagram for externally perturbed oscillations

The axial offset in the reactor power distributions should be maintained near to zero for the stable reactor operation. The value of axial profile index (API) in free running oscillations keeps on increasing but when controller is employed, the flux and power level in top and bottom zone are same hence API is zero. Thus oscillations are completely eliminated (Fig.30).

The displacement of the axial offset control rod to eliminate the neutron flux oscillations in the upper half of the reactor core is shown in the Fig. 31 . At the $30 \mathrm{hrs}$, the AO rods are intentionally disturbed in order to generate the neuron flux oscillations. This will lead to asymmetric build up of Xenon and Iodine in the upper half and lower half of the reactor core. These flux oscillations are allowed to grow until $60 \mathrm{hrs}$. By using an Intelligent Constrained Receding-Horizon Predictive Controller, the oscillations are killed at $60 \mathrm{hrs}$ without operator's intervention.

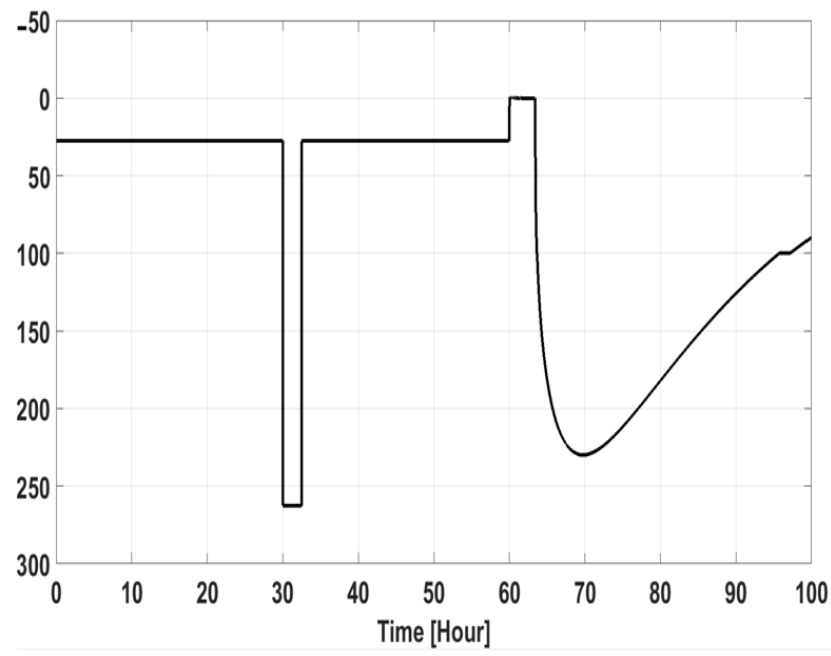

Fig.31. Displacement of AO rods to control rod in the

\subsection{Thermosyphon Heat Transfer Devices and Their Application Strategies}

Thermosyphon Heat Transfer Devices (THTD) are deployable anywhere in the heater section or reactor core to remove the heat passively. These devices have been used in experimental reactors at BARC. Being passively operated, they have been used as decay heat removal systems. THTDs are incorporated within the annular fuel rods to remove the decay heat more effectively. In order to extract the decay heat by using THTDs, different strategies have been developed as shown in the Fig.32, Fig. 33 and Fig. 34.

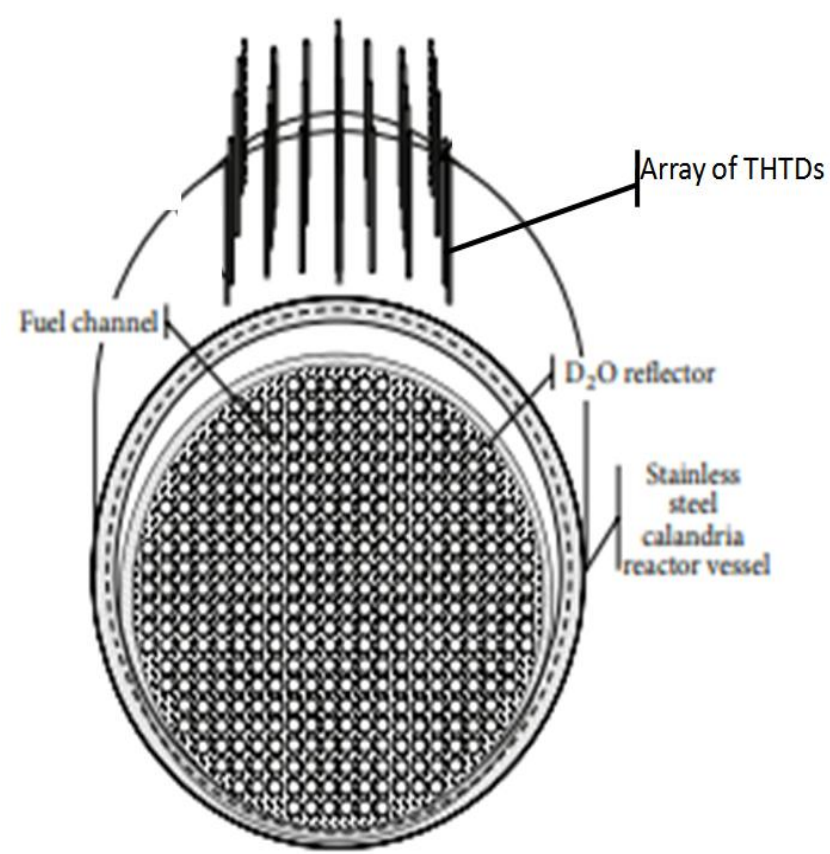

Fig.32: Application strategy for THTDs, in horizontal PHWR reactor core.

The THTDs are mounted and inserted vertically. In case of loss of coolant accident in primary loop, the reactor core is cooled with THTDs passively.

PHWRs have been built in the first stage of three stage Indian power program (Fig.32).

The AHWRs from third stage of the three stage nuclear power plant make use of annular fuels [16]. The THTDs are fitted within the annular fuels in the reactor core. 


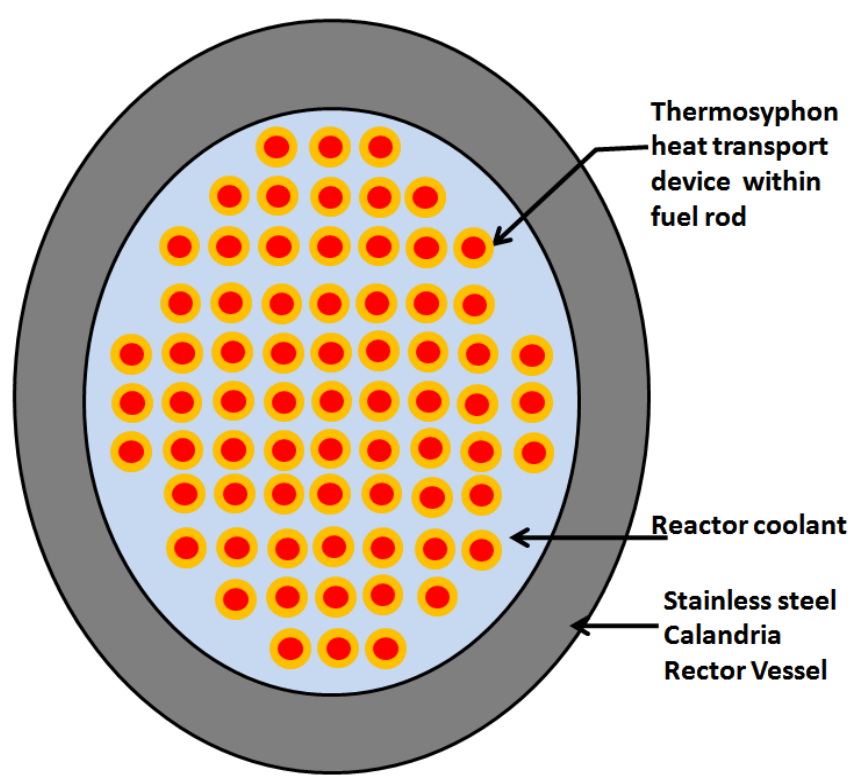

Fig.33: Schematic for locations for THTDs with arrangement in the form of rows and column in reactor core.

Innovative Thermal Reactors (ITR) developed at BARC belonging to Generaion IV reactors make use of radial arrangement (Fig. 34). Instead of arranging the fuel bundles, it is also possible to arrange each fuel elments on the circumference of the circles with increasing radii.

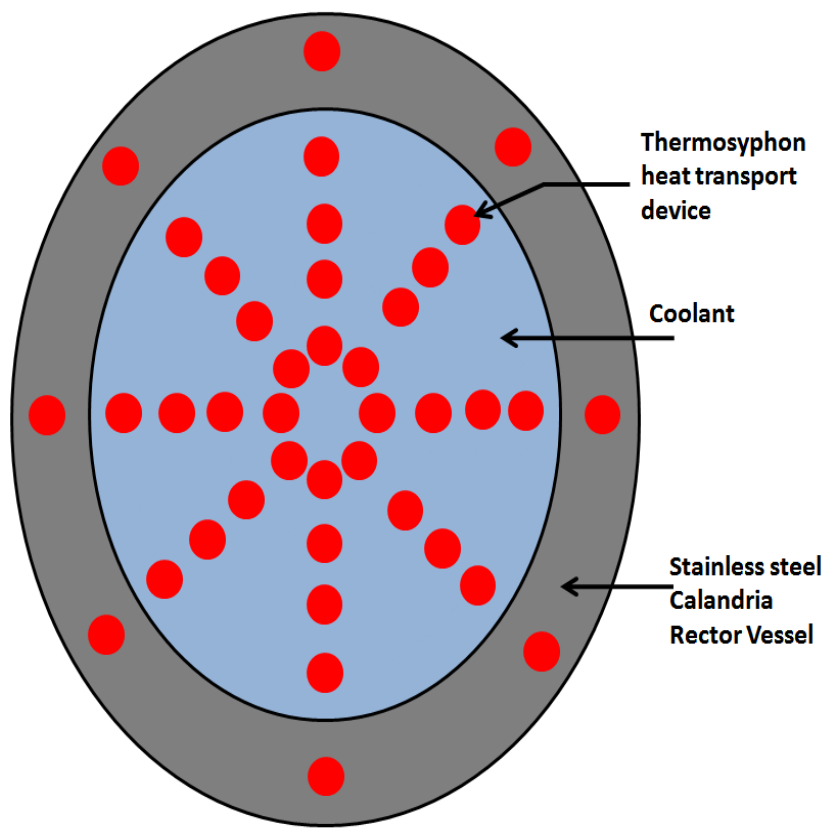

Fig.34: Schematic for locations for THTDs with radial arrangement in reactor core.

Similarly, In case of Innovative Fast Reactor (IFR), the fuel elements are cooled indirectly through several holes in the moderator.

Here, working of Thermosyphon Heat Transfer Device (THTD) has been explained. The generalized design for THTD includes unheated section, heated section, cooler section. The cross over device controls the flow regime of the fluid inside the THTD (Fig.35).

The THTD has an outer diameter $\mathrm{D}_{\mathrm{o}}$ and height $\mathrm{H}$. The inner tube has inner and outer diameters $d_{i}$ and $d_{o}$ respectively in the heated section; the same are $\mathrm{d}_{\mathrm{hi}}$ and $\mathrm{d}_{\mathrm{ho}}$ in cooler section. The outer wall of the heated section is supplied with constant heat flux $\mathrm{q}_{\mathrm{h}}$ (Fig. 36) and the outer wall of the cooler section is in contact with secondary fluid having a mean temperature of $\mathrm{T}_{\mathrm{s}}$.

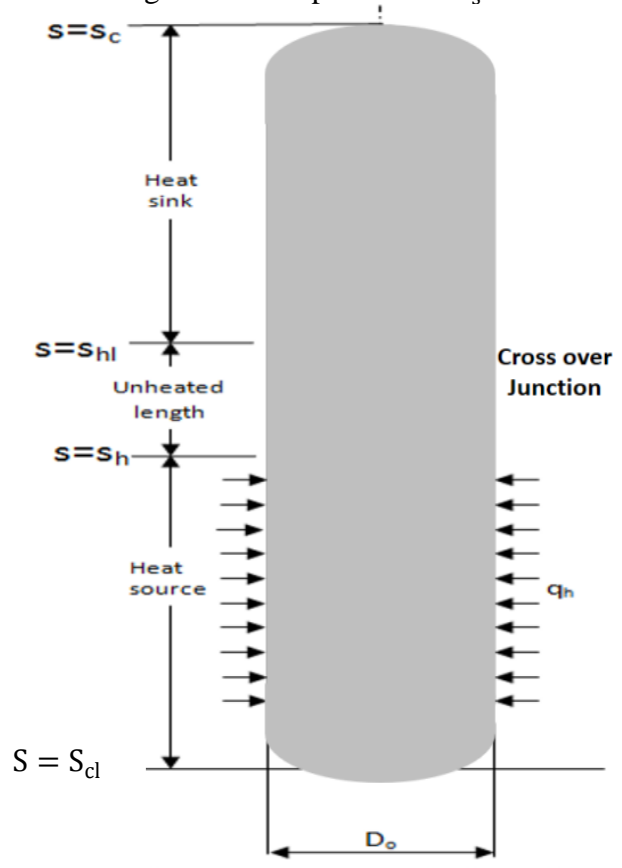

Fig. 35: Model for THTD

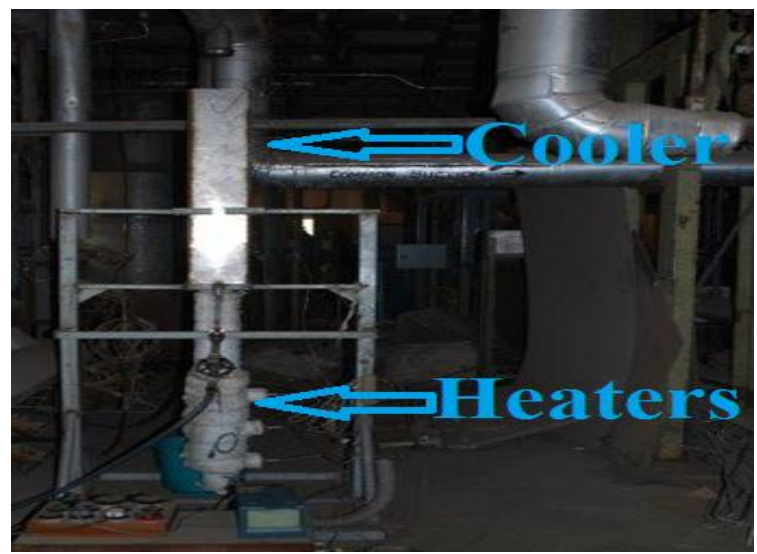

Fig.36: Experiment Setup for Thermosyphon Heat Transfer Device

\subsubsection{Design Analysis for THTD- I}

The heat and mass transfer analysis for any system is completed with conservation of energy, mass and momentum equations over system under the consideration.

THTD-I is filled with incompressible fluid in the close loop (Fig.37). The first equation is conservation of momentum equation including frictional losses over the closed thermosyphon loop. The fluid mass flow rate is not dependent on the location of the fluid in the loop as indicated by the second equation. Insulating material is used to insulate the THTD to avoid heat exchange with surrounding. The flow-rate of fluids during the steady state is simulated as function of the space by conservation equations.

$\frac{L_{t}}{A} \frac{\partial w}{\partial t}=\int g \rho_{0} \beta T d h-\frac{\mathrm{fL}_{\mathrm{eff}} \mathrm{W}^{2}}{2 \mathrm{D} \rho_{0} \mathrm{~A}^{2}}$

$\frac{\partial \mathrm{w}}{\partial \mathrm{s}}=0$

where, effective length taking into account the local losses is denoted by $\mathrm{L}_{\text {eff }}$ and the total length of the loop is denoted by $L_{t}$. Thermal expansion of the fluid generally takes place, when the fluid is heated. The thermal expansion coefficient $(\beta)$ accounts for this phenomenon. At the top most location, the fluid sinks down in the heat sink because of gravity. 
When the liquid moves down, it exchanges heat with secondary. The hot leg, heater, cooler, cold leg are analyzed with the energy conservation equation.

$$
\begin{aligned}
& \frac{\partial \mathrm{T}}{\partial \mathrm{t}}+\frac{\mathrm{W}}{\mathrm{A} \rho_{0}} \frac{\partial \mathrm{T}}{\partial \mathrm{s}}-\alpha \frac{\partial^{2} \mathrm{~T}}{\partial \mathrm{s}^{2}}= \\
& \left\{\begin{array}{lr}
\frac{\mathrm{q}_{\mathrm{h}} \xi_{\mathrm{i}}}{\mathrm{A} \rho_{0} \mathrm{C}_{\mathrm{p}}}-\frac{\mathrm{U}_{0} \zeta_{\mathrm{o}}\left(\mathrm{T}-\mathrm{T}_{\mathrm{mcl}}\right)}{\mathrm{A} \rho_{0} \mathrm{C}_{\mathrm{p}}} & \text { Source } \\
\frac{\mathrm{U}_{\mathrm{hi}} \zeta_{\mathrm{hi}}\left(\mathrm{T}-\mathrm{T}_{\mathrm{mc}}\right)}{\mathrm{A} \rho_{0} \mathrm{C}_{\mathrm{p}}} & \text { Hot leg } \\
-\frac{\mathrm{U}_{\mathrm{wci}}\left(\mathrm{T}-\mathrm{T}_{\mathrm{msc}}\right) \xi_{\mathrm{i}}}{A \rho_{0} \mathrm{C}_{\mathrm{p}}}+\frac{\mathrm{U}_{\mathrm{h} 0} \zeta_{\mathrm{ho}}\left(\mathrm{T}_{\mathrm{mhl}}-\mathrm{T}\right)}{A \rho_{0} \mathrm{C}_{\mathrm{p}}} & \text { Sink } \\
\frac{\mathrm{U}_{\mathrm{i}} \zeta_{\mathrm{i}}\left(\mathrm{T}_{\mathrm{mh}}-\mathrm{T}\right)}{A \rho_{0} \mathrm{C}_{\mathrm{p}}} & \text { cold leg }
\end{array}\right.
\end{aligned}
$$

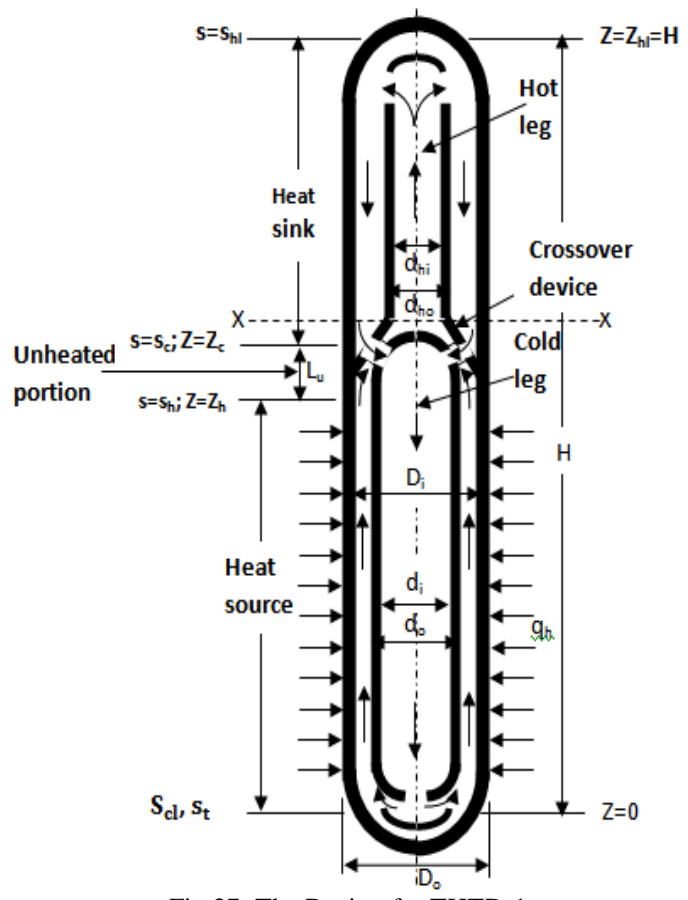

Fig.37: The Design for THTD-1

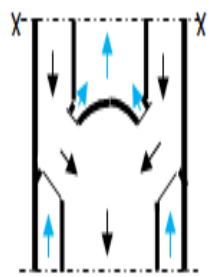

Fig.37a: Front View for cross-over junction

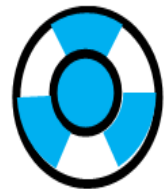

Fig.37b: Top view for Cross-over junction

where, $\quad \zeta_{i}=\pi d_{i}, \zeta_{h o}=\pi d_{h o}, \zeta_{h i}=\pi d_{h i}, \xi_{i}=\pi D_{i}, \zeta_{o}=$ $\pi d_{o} \quad$ where, $\quad \zeta_{h i}=\pi d_{h i} ; \xi_{i}=\pi D_{i} ; \zeta_{o}=\pi d_{o} ; \zeta_{i}=$ $\pi d_{i}, \zeta_{h o}=\pi d_{h o}$. Here, the average liquid temperatures of the cold leg \& average liquid temperature in the cooler primary side, mean hot leg liquid temperature and mean water temperature in heater section are respectively denoted by $\mathrm{T}_{\mathrm{mcl}}, \mathrm{T}_{\mathrm{mc}}, \mathrm{T}_{\mathrm{mhl}}, \mathrm{T}_{\mathrm{mh}}$.
Also, the overall heat transfer coefficients based on the inside wall of the sink, cold leg inside walls and hot leg inside walls, cold leg outside, hot leg outside walls are respectively given by $U_{w c i}, U_{i}, U_{h i} U_{0}, U_{h o}$. As the inner wall has been made of an insulating material, the radial heat transfer conduction is negligible. For the steady state, the Eq. 16 is modified as described below,

$\frac{\mathrm{W}}{\mathrm{A} \rho_{0}} \frac{\partial \mathrm{T}}{\partial \mathrm{s}}-\alpha \frac{\partial^{2} \mathrm{~T}}{\partial \mathrm{s}^{2}}=$

$\left\{\begin{array}{lr}\frac{q_{h} \xi_{i}}{A \rho_{0} C_{p}}-\frac{U_{0} \zeta_{o}\left(T-T_{m c l}\right)}{A \rho_{0} C_{p}} & \text { Source } \\ \frac{U_{h i} \zeta_{h i}\left(T-T_{m c}\right)}{A \rho_{0} C_{p}} & \text { Hot leg } \\ -\frac{U_{w c i}\left(T-T_{m s c}\right) \xi_{i}}{A \rho_{0} C_{p}}+\frac{U_{0} \zeta_{h o}\left(T T_{m h l}-T\right)}{A \rho_{0} C_{p}} \text { Sink } \\ \frac{U_{i} \zeta_{i}\left(T_{m h}-T\right)}{A \rho_{0} C_{p}} & \text { cold leg }\end{array}\right.$

\subsubsection{Analysis for THTD-II}

The Fig.38. illustrates the design for THTD-II. Due to heating action, the lower density fluid moves upward towards the heat sink section. In this design, there is no sandwitched crossover device. THTD-II can't transfer the heat from heater to cooler section, when the sink height is larger than buoyancy driven head.

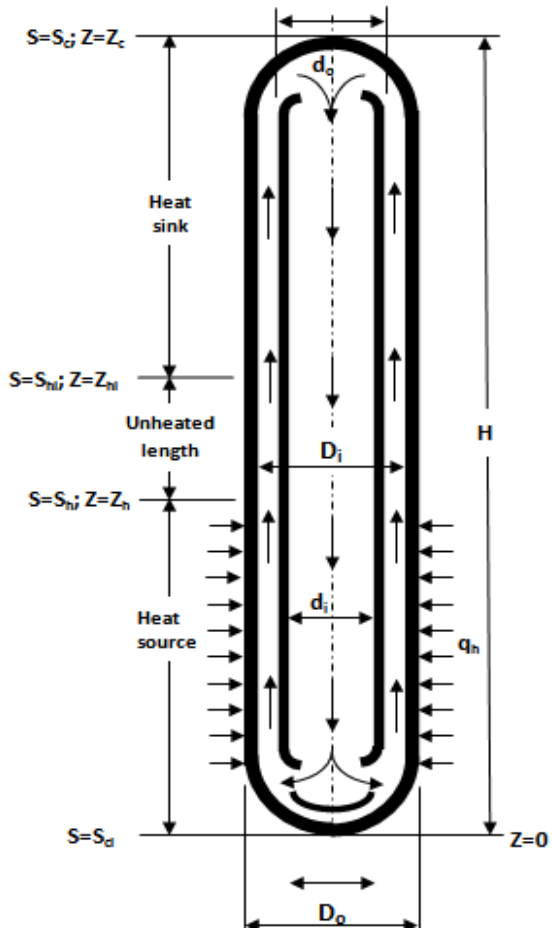

Fig.38: The design for THTD-2

In the mathematical model used for analysis, same conservation of mass and momentum equations are applicable for THTD-2. The energy conservation equation for the THTD2 is modified as described below,

$\frac{\partial \mathrm{T}}{\partial \mathrm{t}}+\frac{\mathrm{W}}{\mathrm{A} \rho_{0}} \frac{\partial \mathrm{T}}{\partial \mathrm{s}}-\alpha \frac{\partial^{2} \mathrm{~T}}{\partial \mathrm{s}^{2}}=$ 


$$
\begin{cases}\frac{\mathrm{q}_{\mathrm{h}} \zeta_{\mathrm{i}}}{\mathrm{A} \rho_{0} \mathrm{C}_{\mathrm{p}}}-\frac{\mathrm{U}_{0} \zeta_{\mathrm{o}}\left(\mathrm{T}-\left[\mathrm{T}_{\mathrm{mcl}}\right]_{\mathrm{h}}\right)}{A \rho_{0} \mathrm{C}_{\mathrm{p}}} & \text { Source } \\ -\frac{\mathrm{U}_{\mathrm{w}} \zeta_{\mathrm{hi}}\left(\mathrm{T}-\mathrm{T}_{\mathrm{w}}\right)}{A \rho_{0} \mathrm{C}_{\mathrm{p}}}-\frac{\mathrm{U}_{\mathrm{o}} \zeta_{\mathrm{o}}\left(\mathrm{T}-\left[\mathrm{T}_{\mathrm{mcl}}\right]_{\mathrm{hl}}\right)}{A \rho_{0} \mathrm{C}_{\mathrm{p}}} & \text { Hot leg } \\ -\frac{\mathrm{U}_{\mathrm{ci}}\left(\mathrm{T}-\mathrm{T}_{\mathrm{msc}}\right) \xi_{\mathrm{i}}}{A \rho_{0} \mathrm{C}_{\mathrm{p}}}+\frac{\mathrm{U}_{0} \zeta_{\mathrm{ho}}\left(\mathrm{T}-\left[\mathrm{T}_{\mathrm{mcl}}\right]_{\mathrm{c}}\right)}{A \rho_{0} \mathrm{C}_{\mathrm{p}}} & \text { Sink } \\ \frac{\mathrm{U}_{\mathrm{i}} \zeta_{\mathrm{i}}\left(\mathrm{T}_{\mathrm{i}}-\mathrm{T}\right)}{\mathrm{A} \rho_{0} \mathrm{C}_{\mathrm{p}}} & \text { cold leg }\end{cases}
$$

Here, $\left[\mathrm{T}_{\mathrm{mcl}}\right]_{\mathrm{hl}},\left[\mathrm{T}_{\mathrm{mcl}}\right]_{\mathrm{h}},\left[\mathrm{T}_{\mathrm{mcl}}\right]_{\mathrm{c}}$ denote mean cold leg temperatures for the hot-leg, heater, and cooler sections respectively. According to the section to be analysed, the terminology $T_{i}$ in the cold leg changes. For example, the term $\mathrm{T}_{\mathrm{i}}$ corresponds to the node in the heater section if it is heater section.

Along the different sections of the loop, by solving the above energy conservation equation, the temperature of the fluid within THTD is evaluated. When the axial conduction is neglected, the Eq. 8 gets modified as given below during the steady state, $\frac{\mathrm{W}}{\mathrm{A} \rho_{0}} \frac{\partial \mathrm{T}}{\partial \mathrm{s}}=$

$$
\left\{\begin{array}{l}
\frac{\mathrm{q}_{\mathrm{h}} \xi_{\mathrm{i}}}{\mathrm{A} \rho_{0} \mathrm{C}_{\mathrm{p}}}-\frac{\mathrm{U}_{0} \zeta_{0}\left(\mathrm{~T}-\left[\mathrm{T}_{\mathrm{mcl}}\right]_{\mathrm{h}}\right)}{A \rho_{0} \mathrm{C}_{\mathrm{p}}} \\
-\frac{\mathrm{U}_{\mathrm{w}} \zeta_{\mathrm{hi}}\left(\mathrm{T}-\mathrm{T}_{\mathrm{w}}\right)}{\mathrm{A} \rho_{0} \mathrm{C}_{\mathrm{p}}}-\frac{\mathrm{U}_{\mathrm{o}} \zeta_{\mathrm{o}}\left(\mathrm{T}-\left[\mathrm{T}_{\mathrm{mcl}}\right]_{\mathrm{hl}}\right)}{A \rho_{0} \mathrm{C}_{\mathrm{p}}} \\
\quad-\frac{\mathrm{U}_{\mathrm{ci}}\left(\mathrm{T}-\mathrm{T}_{\mathrm{msc}}\right) \xi_{\mathrm{i}}}{A \rho_{0} \mathrm{C}_{\mathrm{p}}}+\frac{\mathrm{U}_{0} \zeta_{\mathrm{ho}}\left(\mathrm{T}-\left[\mathrm{T}_{\mathrm{mcl}}\right]_{\mathrm{c}}\right)}{A \rho_{0} \mathrm{C}_{\mathrm{p}}} \\
\frac{\mathrm{U}_{\mathrm{i}} \zeta_{\mathrm{i}}\left(\mathrm{T}_{\mathrm{i}}-\mathrm{T}\right)}{\mathrm{A} \rho_{0} \mathrm{C}_{\mathrm{p}}}
\end{array}\right.
$$

It has been observed that flow rate for fluid (heat transport capability) for THTD-II is lower than that of THTD-I. In THTD-I, the flow rate is higher because, fluid does not exchange heat, when fluid rises above. The THTD II has no cross-over device. In THTD II, when the cooling length is higher than buoyancy driven pressure head, the device II can fail to perform its functioning. The highest temperature in THTD-II is higher than that of THTDI, because of higher heat transport capability by THTD-I, (Fig. 39).

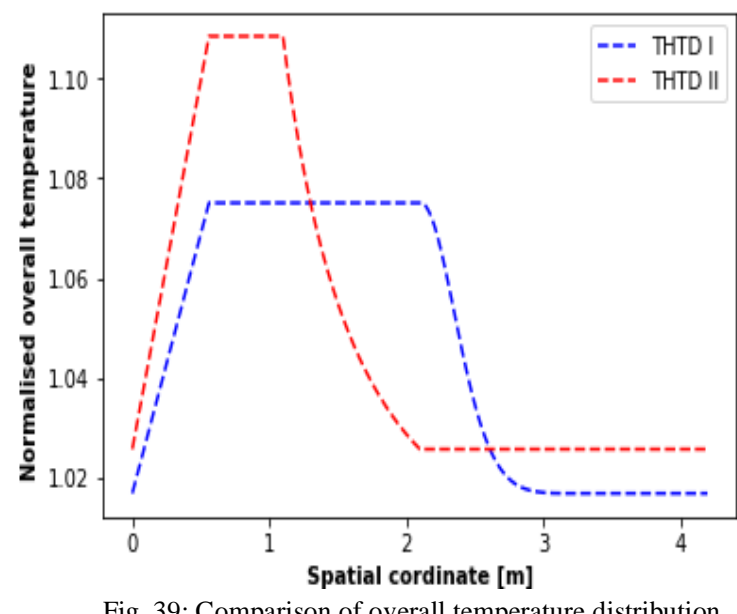

In Fig. 40, the consequence for change in outer diameter has been investigated, keeping the height of loop constant $\&$ the heater power fixed at $1500 \mathrm{~W}$. As the diameter increased, because of reduction in frictional loss, the flow rate is increased.

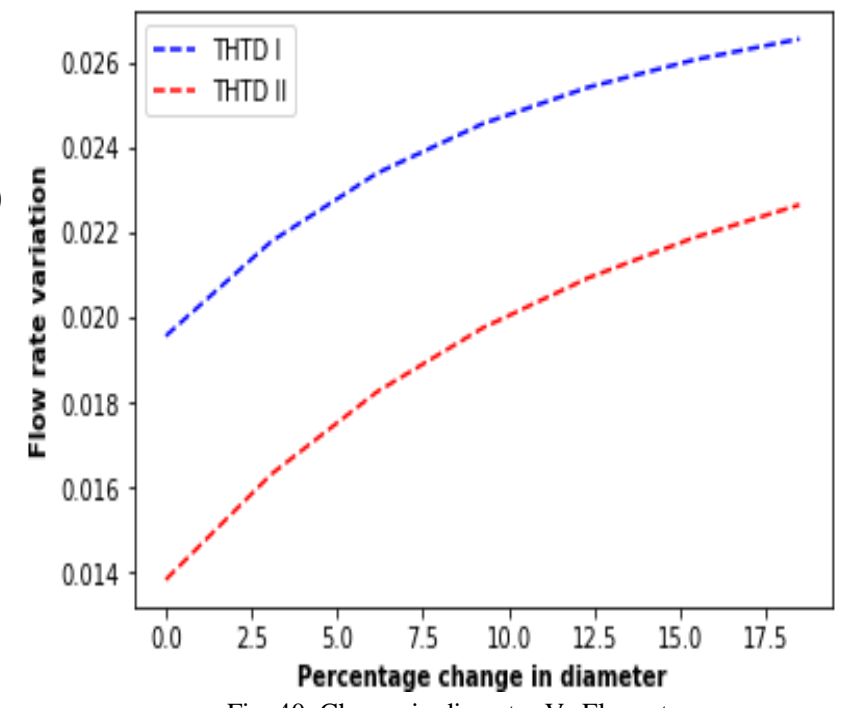

Fig. 40: Change in diameter Vs Flowrate

Bending losses are taken from handbook of hydraulic resistances[25].

Physically, the outer diameter of THTDs fits into central region of annular fuel therefore THTDs function as a moderating device.

\subsection{Detectors to monitor the radioactivity levels}

From reactor operators' health point of view, monitoring the radiation levels surrounding the nuclear reactor is one of the important task during the reactor operation. Saxena et al. have developed ISMRAN detector for the detection of reactor antineutrinos during start-up, shutdown and steady state operations [26]. This detector also helps in determining the reactivity during the steady state and transient conditions, thus it functions as reactivity meter (Fig. 41).

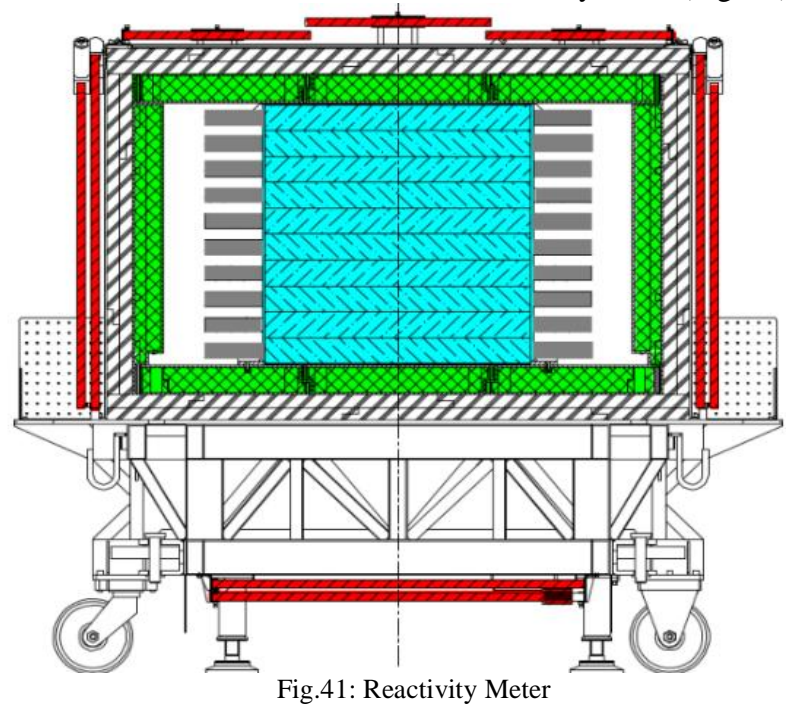

Inside the detector, electron antineutrino reaction with proton takes place with very small interaction cross-section $(6 \times$ $10^{-43} \mathrm{~cm}^{2}$ ) as given below,

$$
\overline{\gamma_{e}}+p \rightarrow e^{+}+n .
$$

The produced positron, having almost all of the energy as that of the incoming neutrino, loses energy in the detector volume through ionization as well as annihilation with an electron which in turn produces two rays of $0.511 \mathrm{MeV}$. The event by the positron and the resulting $\gamma$-rays provide output signal from the detector. 


\subsection{Automation management for safer operation}

For the stable reactor operation, various plant parameters are required therefore software is developed to monitor various parameters. The software provides interactive graphical user interface and allows monitoring of various parameters during the normal and off-normal transients (Fig. 42).

In order to ensure the maintenance and operational safety, the online supervision of plant status is one of the most important tasks. Conventionally, the fault threshold levels for each plant parameter are preset and an alarm signal is generated as soon as the observed signal shows the anomaly. However, in many cases, when an anomaly is observed, it may be too developed to undo. Therefore, a model-based method has been used, which is better for early fault detection than the conventional threshold levelbased systems. For a layman operator having no knowledge about plant dynamics, the automation is required and therefore it is embedded in the plant management software.

In the past, several cases are experienced in various labs hacking vital information and procedures which are attempted by external agencies. In order to prevent any type of external threat and data hacking, the computer rooms are protected with secured network systems to prevent cyber-attacks by external agencies.

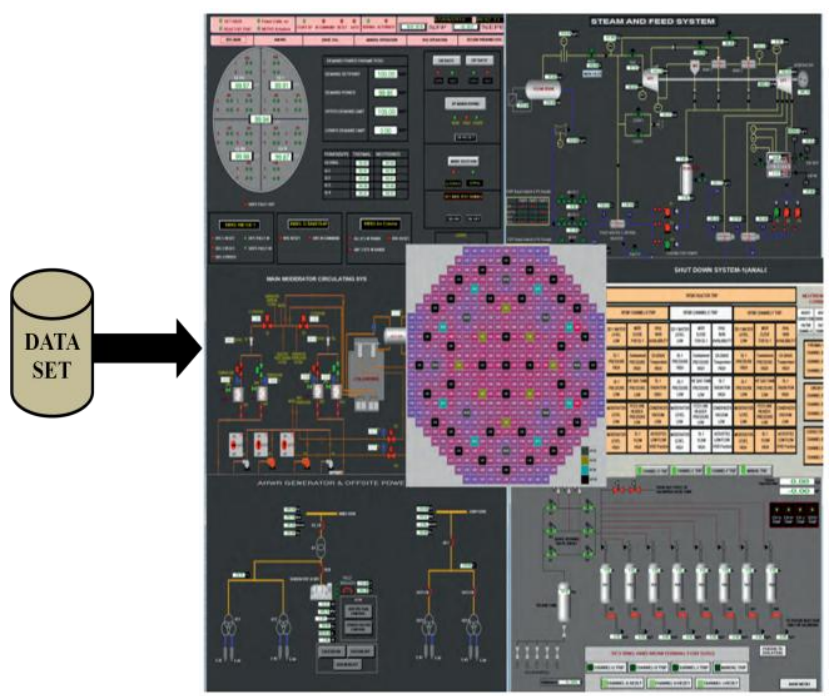

Fig.42: Autonomous overall plant management for Advance Heavy Water Reactor

Interestingly, the PHWR at Kaiga has set world record of continuous operation for 941 days, at a Plant Load Factor of about 99.3\% without any incident (941 days from May 13, 2016 to Dec. 10, 2018). Earlier, the record of uninterrupted reactor operation was held by Unit 2 of Heysham power plant. This reactor was operated from February 18, 2014 to September 15, 2016 for 940 days.

\section{Recycling of the spent fuel}

The first Indian fast breeder reactor achieved criticality and started operation when there were no computers available and other nations were not reliable for co-operation (Fig. 43). This reactor has been running successfully without single failure since the past several decades. It makes use of sodium bonded metallic fuel pins. The fuel with BISO and TRISO coated particles developed at $\mathrm{BARC}$ has been also irradiated in this reactor.

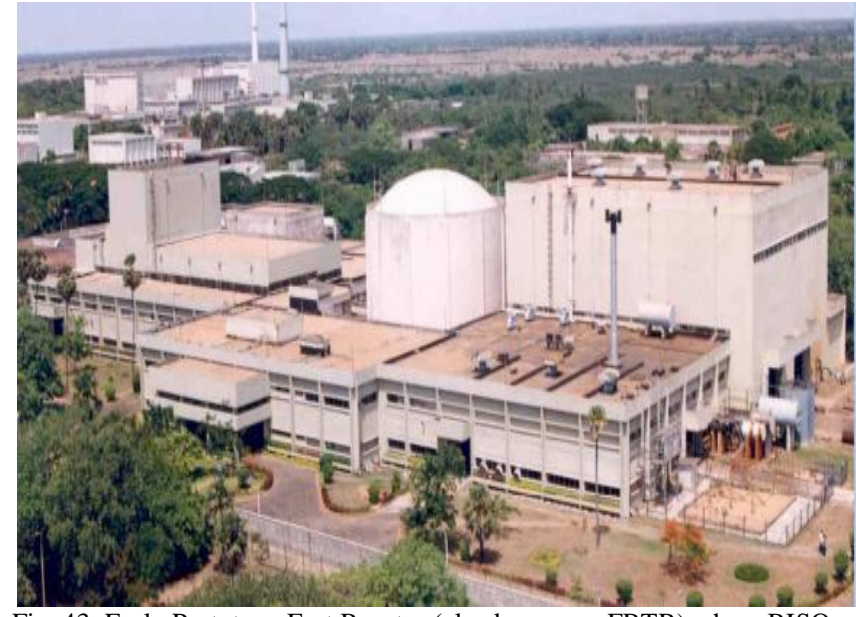

Fig. 43: Early Prototype Fast Reactor (also known as FBTR) where BISO and TRISO particle fuels are irradiated.

Irradiation of TRISO particles is accomplished within high temperature environment of the sodium-cooled fast reactor. The annular fuels described earlier are utilized for fast reactor. The discharge of Sodium though the piping is demonstrated in Fig. 44. Through the operational experience gained so far, a new 500MWe sodium cooled reactor has been built-up at Kalpakkam, India (Fig. 44 and Fig. 45).

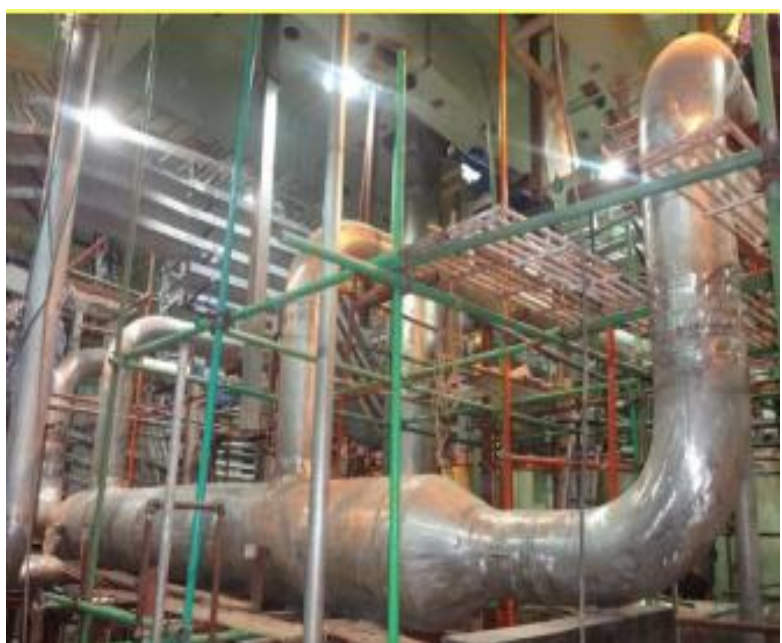

Fig.44: Sodium piping for fast breeder reactor [27]

The plutonium recovered from the burned fuel after reprocessing has been used to manufacture the fresh fuel along with Thorium at NFC, Hyderabad. This fresh fuel will be used as input for 3rd stage of the Indian Nuclear Power Program.

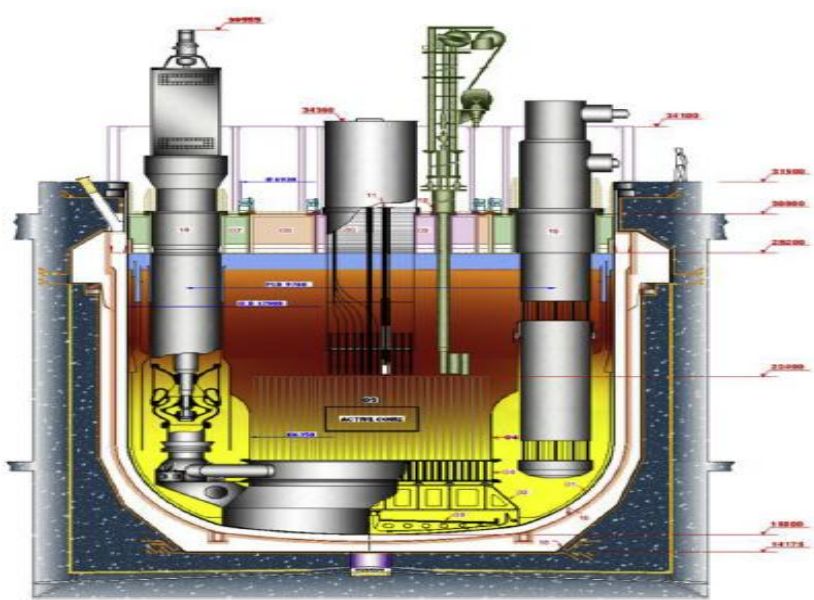

Fig.45: FBR reactor core [28]. 
Moreover, the developed fast reactor can burn different actinides reducing the nuclear waste drastically to lower level, hence it supports not only for non-proliferation but also for radioactive waste management. The $\mathrm{U}^{233}$ obtained from $\mathrm{Th}^{232}$ surrounding the FBR fuel, is used as input fuel for Advance Heavy Water Reactors (AHWRs) to be started in the third stage of Indian three stage nuclear power program. Without usage of $\mathrm{U}^{233}$, AHWRs cannot attain the criticality and start up, hence usage of $\mathrm{U}^{233}$ is necessary to run third stage reactors. The AHWR criticality layout is shown in Fig. 46. The absorber rod locations are shown with pink color rods in this layout.

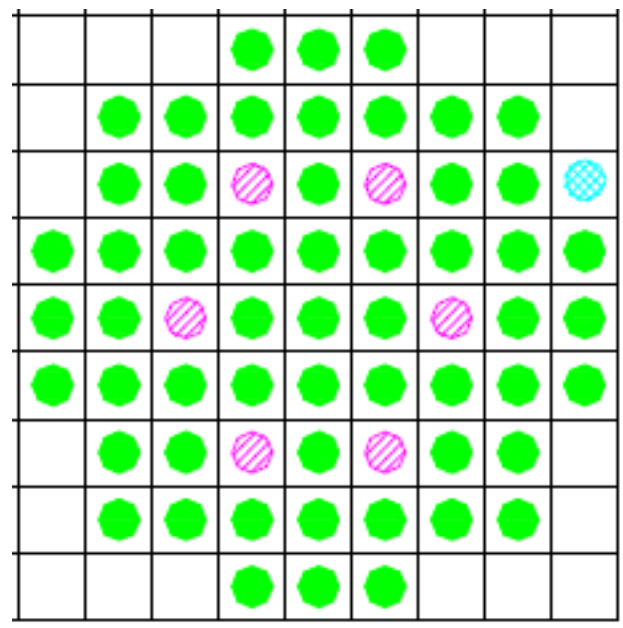

Fig.46: AHWR criticality layout

The radioactive decay chain of $\mathrm{Th}^{232}$ is delineated in Fig. 47 .

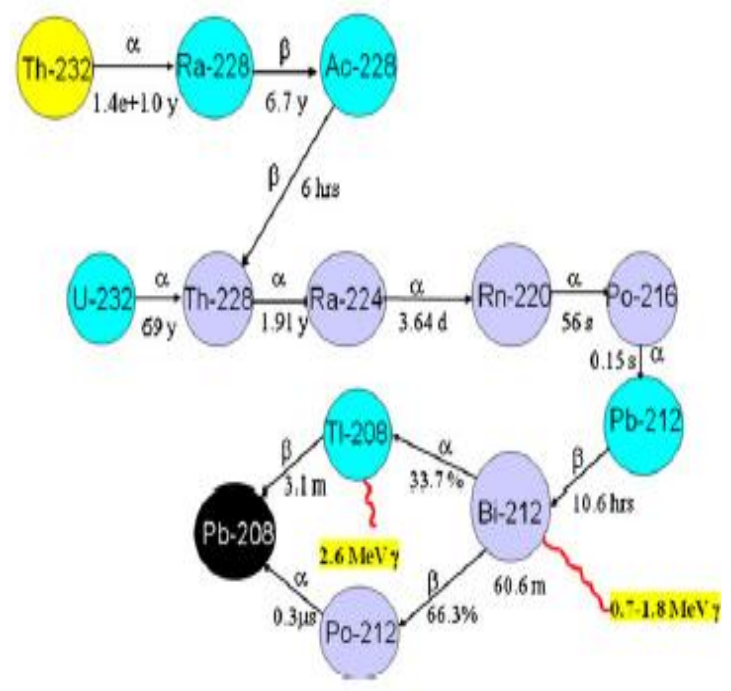

Fig.47: Thorium Decay Chain

The buildup of $\mathrm{U}^{233}$ when Thorium is irradiated in the AHWR from third stage has been shown in the Fig. 48 as function of fluence. Without usage of $\mathrm{U}^{233}$, equilibrium fuel cycles can't be established for AHWR. Better proliferation resistance of Advance Heavy Water reactor (Plutonium 10\% lower in used fuel than in a PWR) has been proved by the scientists from Brookhaven National Lab [29].The innovative fuels developed at BARC improve the proliferation resistance of reactors for three-stage Nuclear Power Program.

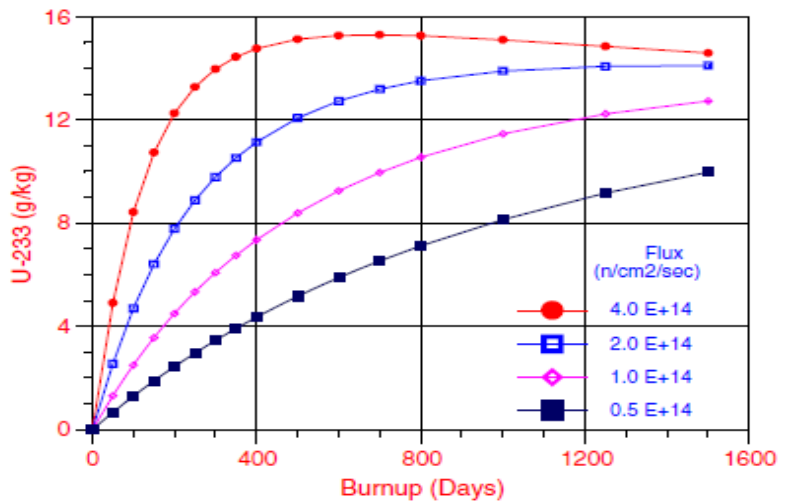

Fig.48: $\mathrm{U}^{233}$ build up as function of fluence

The Fig. 49 overviews and explains Three-stage Nuclear Power Program to utilize nuclear energy. These stages are connected with each other utilizing the nuclear waste.

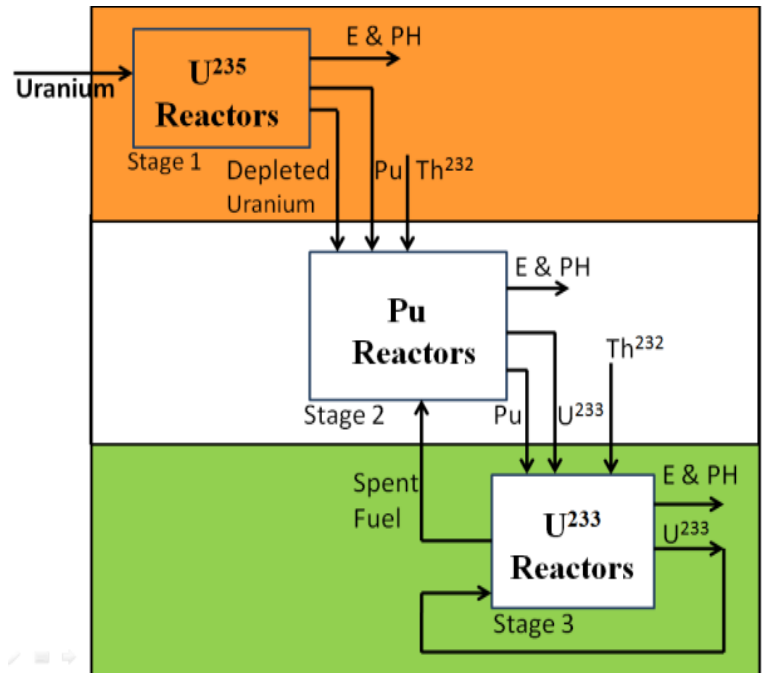

Fig.49: Three-stage Nuclear Power Program from the constitution of India.

Parallel to AHWRs, GEN IV reactors including IHTR, IMSBR, etc. have been developed to utilize thorium fuel in the third stage of Indian Nuclear Power Program (see the Table 4). In order to fuel and operate GEN IV reactors, sufficient amount of $\mathrm{U}^{233}$ inventory is required. The $\mathrm{U}^{233}$ inventory will come from the output of second stage. Plutonium-239 is also one of the three main isotopes $\left(\mathrm{Pu}^{239}, \mathrm{U}^{233}, \mathrm{U}^{235}\right)$ which can be utilized as fuel in thermal spectrum nuclear reactors. The Plutonium inventory is burned in the third stage also, in order to achieve criticality and establish equilibrium fuel cycles for $\mathrm{U}^{233}$. Hence burning $\mathrm{Pu}^{239} \& \mathrm{U}^{233}$ in second \& third stage reactors along with Thorium is solution to the nuclear proliferation. The first, second and third stages are expected to generate $12 \mathrm{GW}, 300 \mathrm{GW}$ and $500 \mathrm{GW}$ of power respectively, including $10 \%$ process heat energy in each stage.

Thus, the developed safer nuclear fuels enable continuous desirable Hydrogen production (for peaceful applications) on the secondary side of intermediate heat exchanger through various low temperature Hydrogen production cycles. Nonetheless, the fuels in the form of BISO and TRISO particles which are capable of withstanding in high fluence and temperature environment enable Hydrogen production through high temperature cycles e.g. Sulfur-Iodine (S-I) cycle. 
Table 4: Indian GEN IV Innovative Nuclear Reactors Development

\begin{tabular}{|c|c|c|c|c|}
\hline $\begin{array}{l}\text { Sr. } \\
\text { No. }\end{array}$ & Indian reactor ${ }^{\text {t }}$ & Nuclear Fuel used ${ }^{\text {tet }}$ & Stage & $\begin{array}{l}\text { Generations in } \\
\text { reactor } \\
\text { technology }\end{array}$ \\
\hline 1 & Apsara & $\mathrm{U}^{233} \mathrm{Al}$ alloy & I & Generation I \\
\hline 2 & Cirus & Natural Uranium & I & Generation I \\
\hline 3 & Dhruva & Natural Uranium & I & Generation I \\
\hline 4 & Zerlina & Natural Uranium & I & Generation I \\
\hline 5 & Indian Pressurized Water Reactor & Shortage of $\mathrm{U}^{235}$, so not prioritized & I & Generation III+ \\
\hline 6 & Pressurized Heavy Water Reactor & Uranium oxide & I & Generation III+ \\
\hline 7 & $\begin{array}{l}\text { Fast Breeder Test Reactor } \\
\text { (Early Prototype Fast Reactor) }\end{array}$ & $\begin{array}{l}* \text { Plutonium-Uranium mixed } \\
\text { carbide fuel } \\
*\left(\mathrm{UC}_{2} \& \mathrm{ThC}_{2}\right) \text { TRISO coated particles } \\
* \text { Thorium dioxide }\end{array}$ & II & Generation I \\
\hline 8 & Paurnima I & Plutonium Oxide & II & Generation I \\
\hline 9 & Prototype Fast Breeder Reactor & $\begin{array}{l}\text { *Mainly } \mathrm{Pu}^{239} \\
\text { *Plutonium-Uranium mixed } \\
\text { carbide fuel } \\
\left.\text { *( } \mathrm{UC}_{2} \& \mathrm{ThC}_{2}\right) \text { Multi-layered fuel } \\
\text { * Thorium dioxide }\end{array}$ & II & Generation IV \\
\hline 10 & $\begin{array}{l}\text { Innovative Accelerator Driven System } \\
\text { program (with series of } \\
\text { accelerators) }\end{array}$ & *Spent fuels along with Thorium & II & Generation IV \\
\hline 11 & Innovative Gas Cooled Fast Reactor & $\begin{array}{l}\text { *Mainly } \mathrm{Pu}^{239} \\
\text { *Plutonium-Uranium mixed carbide fuel } \\
\left.\text { *( } \mathrm{UC}_{2} \& \mathrm{ThC}_{2}\right) \text { Multi-layered fuel } \\
\text { *Thorium dioxide }\end{array}$ & II & Generation IV \\
\hline 12 & Innovative Lead Cooled Fast Reactor & $\begin{array}{l}\text { *Mainly } \mathrm{Pu}^{239} \\
\text { *Plutonium-Uranium mixed carbide fuel } \\
\left.\text { *( } \mathrm{UC}_{2} \& \mathrm{ThC}_{2}\right) \text { Multi-layered fuel } \\
\text { *Thorium dioxide }\end{array}$ & II & Generation IV \\
\hline 13 & Innovative Fast Reactor-1 & $\begin{array}{l}\text { *Mainly } \mathrm{Pu}^{239} \\
\text { *Plutonium-Uranium mixed carbide fuel } \\
\left.\text { *( } \mathrm{UC}_{2} \& \mathrm{ThC}_{2}\right) \text { Multi-layered fuel } \\
\text { * Thorium dioxide }\end{array}$ & II & -- \\
\hline 14 & Candle type reactor & $\begin{array}{l}\text { *Mainly } \mathrm{Pu}^{239} \\
\text { *Plutonium-Uranium mixed carbide fuel } \\
\left.\text { *( } \mathrm{UC}_{2} \& \mathrm{ThC}_{2}\right) \text { Multi-layered fuel } \\
\text { * Thorium dioxide }\end{array}$ & II & -- \\
\hline 15 & Kamini & $\mathrm{U}^{233} \mathrm{Al}$ alloy & III & Generation I \\
\hline 16 & Paurnima II & $\mathrm{U}^{233}$ Initially $\left(\mathrm{Pu}^{239}-\mathrm{Th}\right) \mathrm{O}_{2}$ & III & Generation I \\
\hline 17 & Paurnima III & $\mathrm{U}^{233} \mathrm{Al}$ alloy Initially $\left(\mathrm{Pu}^{239}-\mathrm{Th}\right) \mathrm{O}_{2}$ & III & Generation I \\
\hline 18 & Advance Heavy Water Reactor & $*\left(\mathrm{U}^{233}-\mathrm{Th}\right) \mathrm{O}_{2} \&\left(\mathrm{Pu}^{239}-\mathrm{Th}\right) \mathrm{O}_{2}$ & III & Generation IV \\
\hline 19 & Innovative High Temperature Reactor & $\begin{array}{l}*\left(\mathrm{U}^{233}-\mathrm{Th}\right) \mathrm{O}_{2} \&\left(\mathrm{Pu}^{239}-\mathrm{Th}\right) \mathrm{O}_{2} \\
* \text { Fuels in carbide form }\end{array}$ & III & Generation IV \\
\hline 20 & Innovative Molten Salt Breeder Reactor & $\begin{array}{l}\text { *Uranium-233 \& Thoria } \\
* \text { Molten Fluorides of Uranium and } \\
\text { Thorium }\end{array}$ & III & Generation IV \\
\hline 21 & Innovative Supercritical Reactor & $*\left(\mathrm{U}^{233}-\mathrm{Th}\right) \mathrm{O}_{2} \&\left(\mathrm{Pu}^{239}-\mathrm{Th}\right) \mathrm{O}_{2}$ & III & Generation IV \\
\hline 22 & Innovative Thermal Reactor-1 & $*\left(\mathrm{U}^{233}-\mathrm{Th}\right) \mathrm{O}_{2} \&\left(\mathrm{Pu}^{239}-\mathrm{Th}\right) \mathrm{O}_{2}$ & III & -- \\
\hline
\end{tabular}




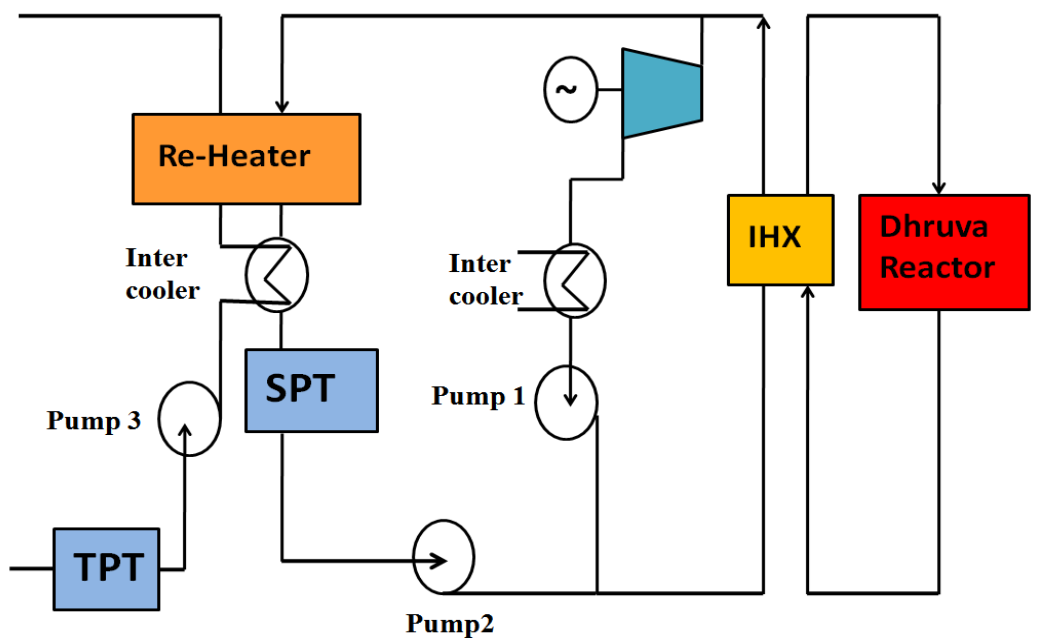

Fig. 50: Process heat for oil sands, IHX- Intermediate Heat Exchanger, SPT-Secondary Process Tank, TPT-Tertiary Process Tank

\section{Some of peaceful applications from Nuclear energy}

Nuclear fuel is high energy density clean fuel. Optimistic scientists consider Nuclear as renewable source of energy because when Uranium is burned with $\mathrm{Th}^{232}$, the spent Uranium fuel can be replenished. The Thorium resources are available abundantly. Nuclear fuels allow development of following environmentally benign applications.

\subsection{Process heat supply for extraction of bitumen from oil sands}

Oil sands, also known bituminous sands, are highly viscous semi- solid form of heavy oil, thus difficult to pump up on the surface. Following methods are used to extract the bitumen:

1. Combustion Overhead Gravity Drainage

2. Steam Assisted Gravity Drainage

3. Vapor Extraction

4. Toe to Heel Air Injection

5. Cold Heavy Oil Production with Sand

6. Surface Mining

7. Cyclic Steam Stimulation

The process heat required in these methods is supplied from nuclear reactor. The high temperature and high pressure tertiary fluid is used to extract the bitumen. The Fig. 50 explains the method to couple the nuclear reactor with oil sand extraction plant. The high temperature, high pressure secondary fluid is divided into two parts and utilized as follows:

(i) The part of process heat supplied to turbines is used to generate the electricity for entire plant

(ii)The remaining part of process heat is used to heat up the tertiary fluid to the temperatures and pressures required extract the product. In one of the methods, the fluid containing bitumen is processed and sent to the central processing unit where Hydrogen is selectively separated from the mixture using membrane with special nano-materials.

\subsection{Applications of secondary storable Hydrogen energy source}

If controlled, the nuclear based continuous mass production of hydrogen with higher efficiency offers several advantages including lower cost of production.

As the secondary fuel Hydrogen has very high heat of combustion $(286 \mathrm{~kJ} / \mathrm{mol})$ with byproduct water; the Hydrogen has very high demand. The clean Hydrogen fuel allows to develop its own several environmentally benign applications.
In rocket science, the Hydrogen fuel has been used by ISRO to launch hundreds of satellites including Mars orbiter (Fig.51). Compared to earth storable liquid and solid propellants, liquid Hydrogen and liquid Oxygen generate much higher thrust with the cryogenic engine. To increase payload capacity, cryogenic engine is useful which very complex system is due to use of propellants at extremely low temperatures.

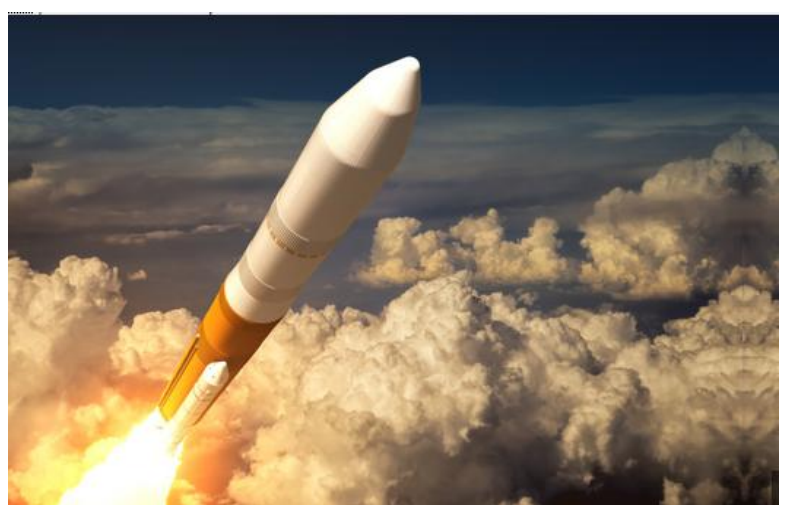

Fig.51: Accomplishment of launching Mars orbiter payload with Hydrogen fuel in single attempt.

Some products have been developed at BARC utilizing environmentally benign Hydrogen fuel.

The first product is Hydrogen driven brushless DC Motor for water pumps. This has added advantage over solar powered pumps due to availability of Hydrogen which allows twenty hours of operation irrespective of whether conditions.

The second product makes use of the Hydrogen to run the stationary electric generator. Inside the generator, Hydrogen and oxygen react with each other with byproduct of water (Fig. 52).

A system with similar dimensions is used in the Hydrogen based battery replacement centre (Fig. 53).

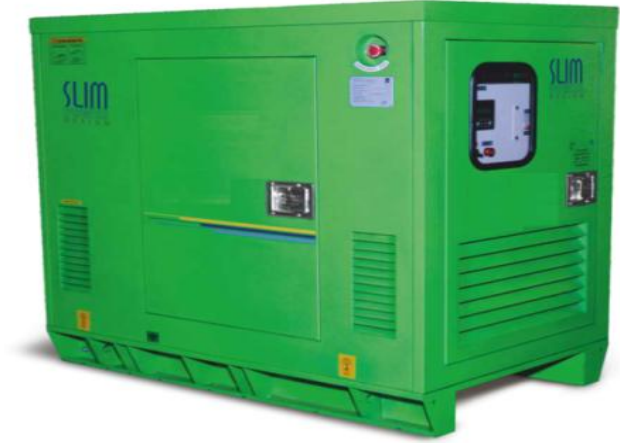

Fig.52: (Stationary) Hydrogen fuelled generator useful for back-up power 
The third product is a mobile plant driven on Hydrogen fuel. This mobile plant can supply additional Hydrogen stored to other Hydrogen operated vehicles. Moreover, this plant utilizes Hydrogen as one of the reactant for fuel cells stacked inside. Since the output voltage of the fuel cell is small $(<1 \mathrm{~V}$ in realistic operating conditions), fuel cells are stacked together in series inside the Hydrogen based charging centre. This method allows replacement of the discharged batteries from battery-operated vehicles. As this plant is mobile, the underground piping cost to carry the Hydrogen gas is eliminated, thus the refuelling operation of Hydrogen fuel is simplified with enhanced safety. The Fig. 53 shows Hydrogen based mobile power plant for the supply of Hydrogen fuel and batteries. In the cities situated near the seashore, the electric boats are an alternative option to commute. These electric boats are run with batteries charged from the mobile plant (Fig. 53).

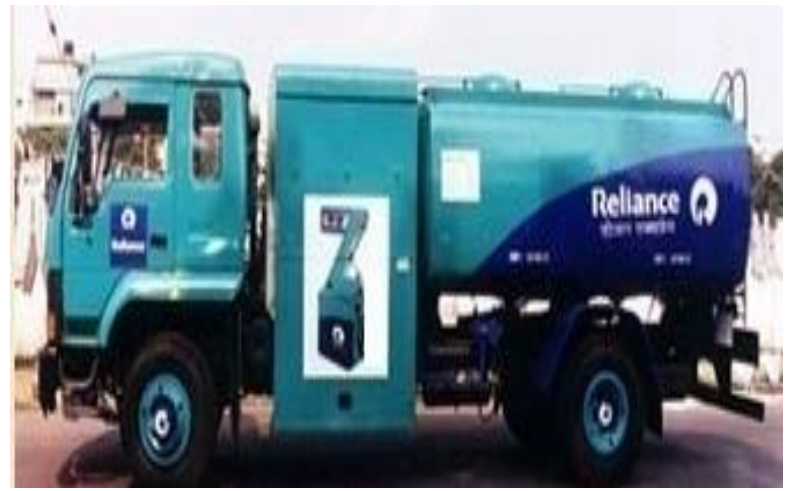

Fig.53: (Mobile) Hydrogen based refuelling \& battery replacement centre.

Additionally, the Hydrogen propelled submarine has been developed at BARC to perform search operations deep under the sea (see Fig. 54). The submarine is fitted with trans-receiver which sends and receives commands from satellite about the current location of the submarine. Using the sensors placed in the submarine, the location of unknown object to be searched deep inside the ocean can be found from the ground station. This Hydrogen fuelled submarine is more environmentally benign than any other diesel engine submarine (Fig. 54) and proliferation resistant.

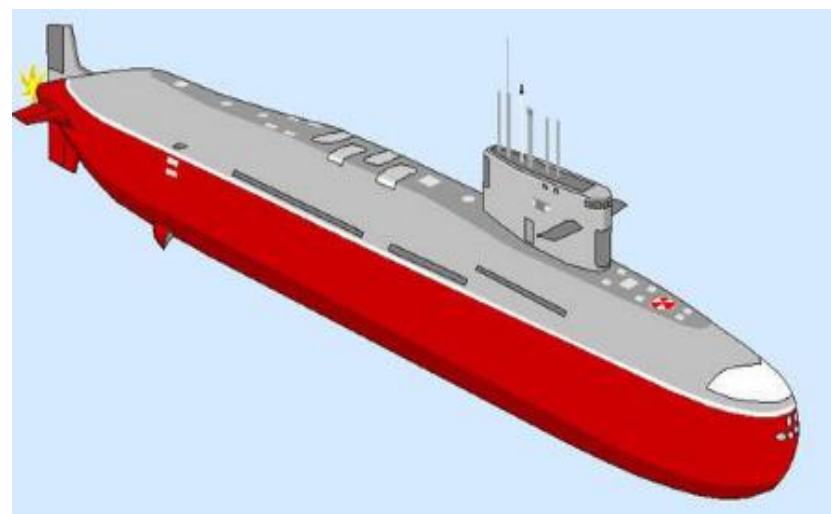

Fig. 54: Hydrogen fuelled submarine for search operations deep under the sea.

\subsection{Dedicated transmission lines for electric locomotives}

India has one of the largest railway networks in the world. In order to provide electric supply for electric locomotives with 24 hours of availability, separate dedicated grids are being constructed running from nuclear reactors. Autotransformer based electric transmission lines are used to supply $25 \mathrm{kV}$ power to the trains, however, some lines transmits power at $50 \mathrm{kV}$ to reduce energy losses (Fig.55).
In order to protect the environment against pollution, Hydrogen fuel trains are used. The Hydrogen trains totally eliminate the high installation cost of overhead wires; therefore Hydrogen trains are likely to be an economical alternative for electric or diesel engine trains. Security is concern in running Hydrogen fuelled trains.

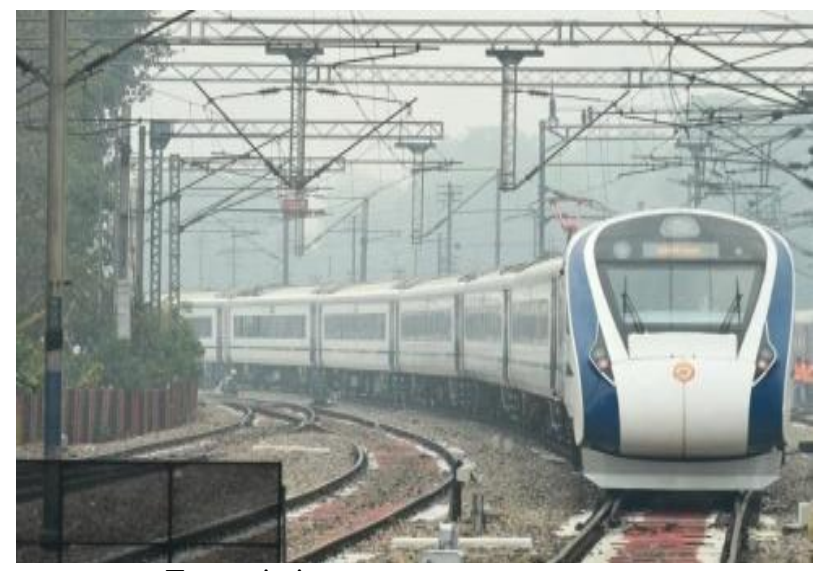

Fig. 55: Transmission lines used for Vande Bharat Express

\subsection{Hydrogen fuelled civilian aircrafts}

From, the experience of a single seated Solar Implulse-2 which revolved around the world with 12 stops, it can be vividly concluded that the lower solar energy density is not sufficient to fly commercialized civilian aircraft.

The usage of biodiesel against petroleum reduces Carbon monoxide and Sulfur contents, thus presently being used. Hydrogen is cleaner fuel than biodiesel fuel. As the volumetric energy density of Hydrogen is 1/3 than that of Methane, large quantity of Hydrogen fuel is required, thus Hydrogen storage is problem. The outside lower temperature of aircraft $\left(-51^{0} \mathrm{C}\right)$ assists in maintaining the Hydrogen in liquid state.

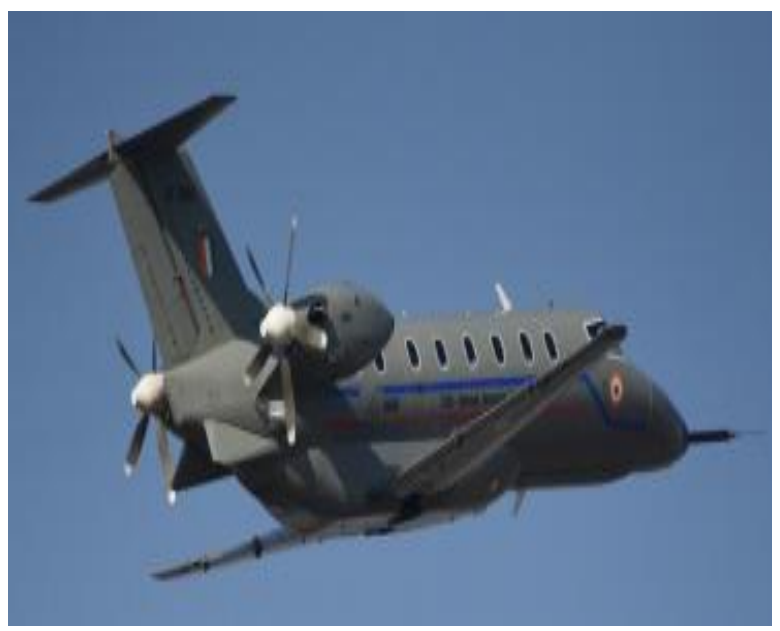

Fig. 56: Civilian Aircraft

National lab of India, has developed civilian aircraft that utilizes environmentally benign Hydrogen fuel (Fig.56). Due to higher energy density of Hydrogen than Solar energy, the planes fuelled with Hydrogen have capacity to carry larger number of passengers or goods with more weight.

\subsection{Recycling of waste plastic}

By recycling the waste plastic, fuels in the form of Hydrocarbons with lesser sulfur contents have been produced for domestic as well as industrial applications by Nasik (Maharashtra) Municipal Corporation (Fig. 57). The heat energy required to convert plastic waste into Hydrocarbons is supplied from nuclear reactor. By 
operating this plant with the help of nuclear power plant, twenty four hours of continuous operation is possible which enable recycling of tons of waste plastic per 24 hours.

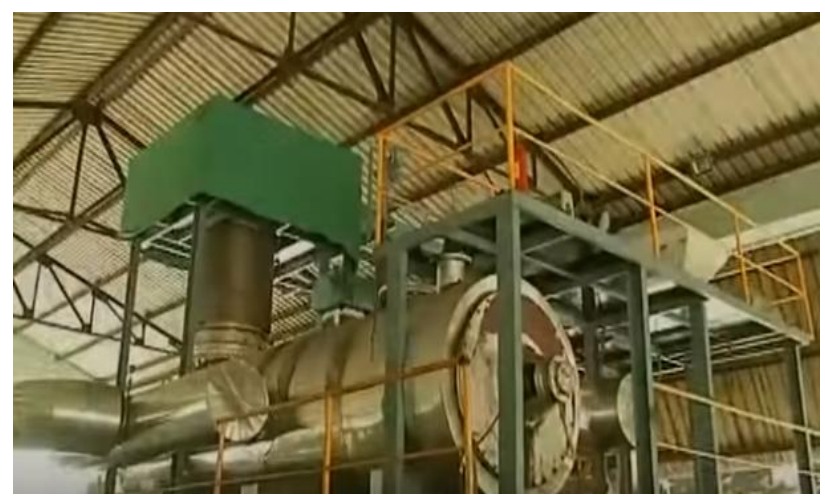

Fig. 57: Recycling of waste plastic

\subsection{Pollution free Iron ore processing}

The Innovative High Temperature Reactor can raise the coolant temperature up to $\approx 1000^{\circ} \mathrm{C}$. The processing of iron ore with the energy obtained from IHX secondary side eliminates the necessity of burning of coals, thus $\mathrm{CO}_{2}$ emissions into the environment get avoided. A prototype high temperature system developed at BARC has been handed over to TATA Steel Limited.

\subsection{Gamma Radiation Processing Plant}

Apart from energy generation required to run machines, efforts have been made for the preservation and disinfection of the food items consumed by humans or animals. The hot and humid climate environment is suitable for the growth of numerous insects and microorganisms that can destroy stored crops and cause spoilage of food easily (Fig.58). The possibility of spoilage of the food is also due to chemical and physiological changes in stored foods.
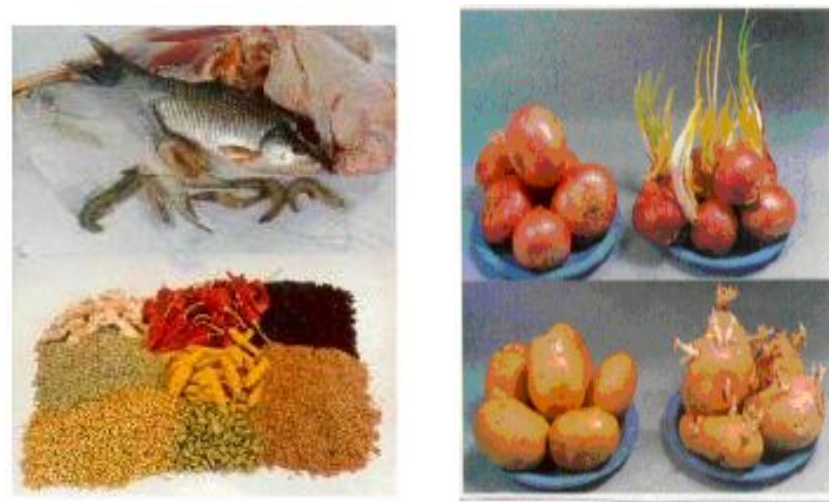

Fig. 58: Spices, frozen meat, poultry and sea-foods, sprout inhibition in bulbs and tubers, fruits, etc. being preserved with the help of radiation processing and other methods developed at BARC.

BARC is focusing on radiation processing along with several other methods so that food items can be preserved for longer durations. All these processes are accomplished inside the Gamma Radiation Processing Plant.

\subsection{Desalination plants for drinkable water}

Every year, over $75 \%$ children \& 40 million people are affected by water borne diseases. About $12 \%$ of the Indian populations are anticipated to have urinary stones; among them, 50\% possibly end up with loss of kidney functions [30]. Shortage of water is another problem for growing population due to unreliability of rain. Because of fluoride contamination in water, children below 14 years of age (nearly six million) suffer from fluorosis. In the country, bacteriological contamination, which leads to diseases like diarrhea, cholera, hepatitis etc., is at risk level. In the ground water of the country, arsenic is also hazardous contaminant risking more than 10 million people. Salinity and hardness in water, contamination due to Iron are other major concern. These problems are mitigated with desalination of seawater technology available.

The desalination is a process of removing salts from the water, making it suitable for human consumption (Fig.59). It is possible to operate the desalination plant on the process heat from the nuclear reactor. A method has been developed to connect the desalination plant with Innovative High Temperature Reactor (IHTR) to utilize the process heat generated by IHTR at BARC.

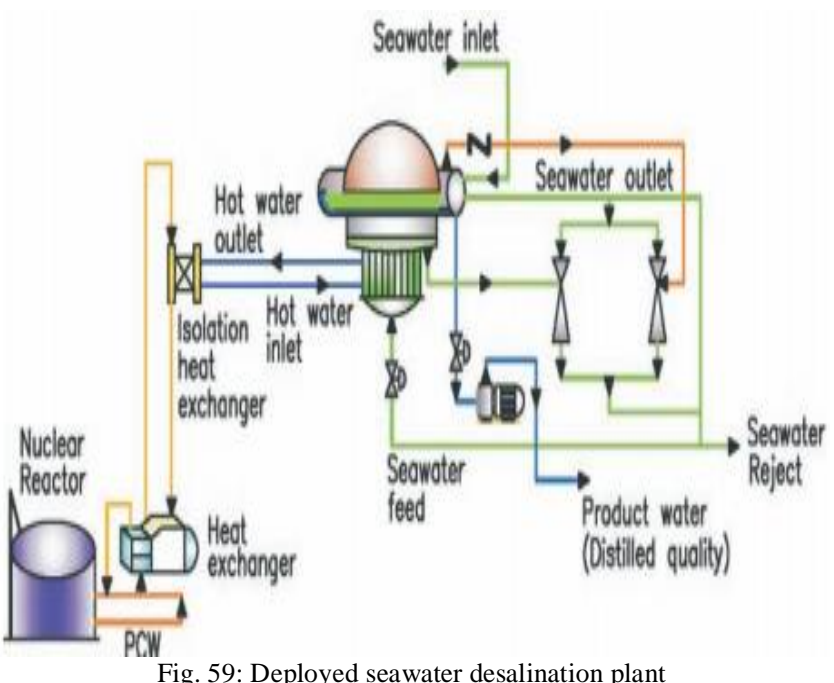

An alternative method has been established and developed at BARC which utilizes Multi-Effect Distillation using Thermo Vapour Compressor effectively called as MED-TVC for the production of low conductivity distilled quality water by using low or medium pressure steam and electricity.

\subsection{Medical applications developed from spent fuel}

Out of many applications, for brevity, here only the application of $\mathrm{Ru}^{106}$ plaque in brachytherapy is explained. Ru bearing Sealed Source is used for Eye Cancer Treatment Applications. Prithwish Sinharoy et. al have patented $\mathrm{Ru}^{106}$ bearing sealed source [31]. This Ru based plaque source is developed, right from the separation of the fissiongenic radionuclide from High Level Waste (HLW) followed by its immobilization onto the silver substrate and eventually its encapsulation into silver plaque indigenously. Thus, the availability of $\mathrm{Ru}^{106}$ greatly help in reducing the cost of brachytherapy and save vision.

\subsection{Nuclear Security}

All the matter in the world is composed of atoms with its constituents. Each atom has a nucleus with one or more electrons in its orbits around the nucleus. Therefore, Nuclear Security has a very broad spectrum. Nuclear security is the detection and prevention of, and response to unauthorized access, unauthorized establishment without permissions, illicit transfer or other malicious acts involving radiological or hazardous material or their associated facilities. However, nuclear security is different from nuclear safety, which involves prevention, mitigation of and protection against accidents involving nuclear material or related facilities that could give further rise to radiation hazards.

In India, Atomic Energy Regulatory Board reviews the nuclear security within the boundary of a nuclear facility which is integrated with the technical design of the facility. India has devised a Design Basis Threat document for protection at its facilities. The national Design Basis Threat takes into account the existing threat from saboteurs, terrorists, thieves, malicious actors, their characte- 
ristic capabilities as well as possibility of the threats. An independent regulatory body from AERB audits physical protection system, regularly. In the daily practice of nuclear security, India's national system of Nuclear Material Accounting \& Control (NUMAC) along with personnel reliability measures plays vital roles

\subsubsection{Technological advancement}

Two technological dimension aspects for the nuclear security in India have been investigated The first one is the design and deployment of secure radiation detectors, portals, secure communication networks, real-time tracking systems, Radio Frequency ID cards, sensors, infra-red cameras and barriers with similar technologies. These supportive technologies are developed indigenously. The second technological dimension includes the development of procedures for nuclear fuel cycle technologies and proliferation resistant nuclear fuel technology which lowers the risk of a nuclear safety and security breach. India has been using closed fuel cycles with Thorium \& Plutonium that obviate both the buildup of stockpiles as well as the necessity to store large amounts of spent fuel in underground repositories containing $\mathrm{U}^{233}, \mathrm{U}^{235}, \mathrm{Pu}^{239}$ which could be easily accessed by malefactors in the future.

Indian scientists have designed proliferation resistant reactors e.g Advanced Heavy Water Reactor (AHWR) along with other $3^{\text {rd }}$ stage reactors using Thorium, which also produce high energy gamma-emitter $\mathrm{U}^{232}$ (as a by-product), that makes use and access for the spent fuel by unauthorized non-state actors difficult. Moreover, the technologies for vitrification of high-level radioactive waste have been developed which have the benefit of making access to waste by terrorists intending to fabricate a radiological device, difficult. India has achieved impeccable record on nuclear nonproliferation.

\subsubsection{International co-operation for nuclear security}

In order to develop international co-operation for nuclear energy security, the Global Centre for Nuclear Energy Partnership (GCNEP) has been established, in India. Having India already advanced nuclear engineering technologies, GCNEP also educates and encourages to foreigners for the usage of nuclear energy.

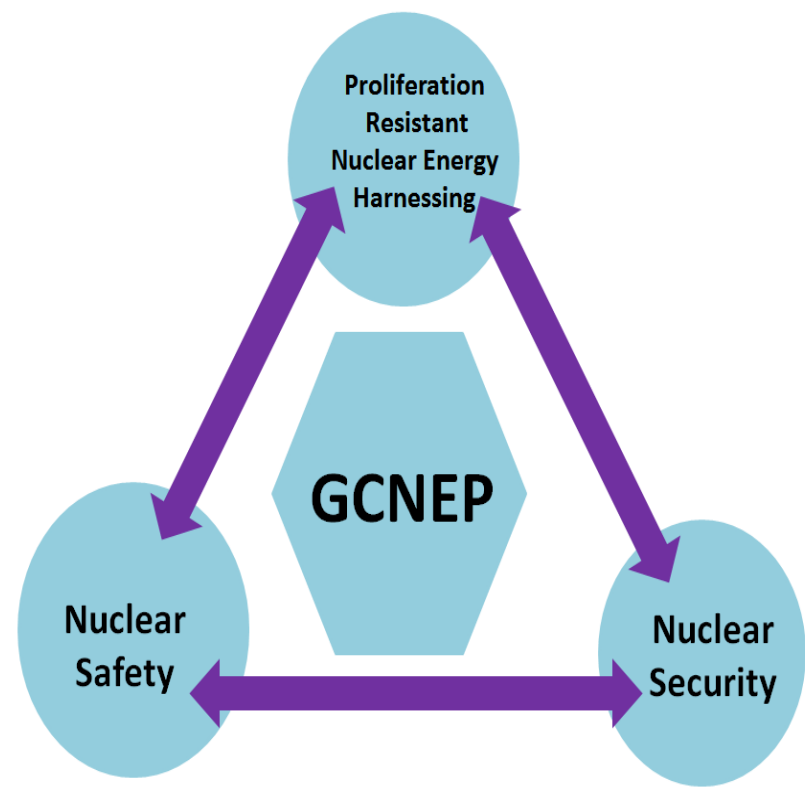

Fig. 60: GCNEP for international co-operation for nuclear energy security

GCNEP organizes and imparts the following in English

1. School of Advanced Nuclear Energy System

Studies (SANESS)

2. School on Radiological Safety Studies (SRSS)

3. School of Nuclear Security Studies (SNSS)

4. School for Studies on Applications of

Radioisotopes and Radiation Technologies (SARRT)

\section{School of Nuclear Material Characterization} Studies (SNMCS)

\subsubsection{Leadership for Nuclear Security}

India has contributed one million USD to the Nuclear Security Fund (NSF) of IAEA recently. Having established impeccable record on nuclear nonproliferation, India is a well-known leading party to the global initiative to combat against nuclear terrorism and has pioneered technological advancement for nuclear detection, forensics, response as well as mitigation.

A well-coordinated style attack inside Metropolitan cities of India breaching the peace through the agents like Ajmal Kasab has reflected various terrorist originations. Thereafter, Dr. Manmohan Singh hosted a meeting of Sherpas for the Nuclear Security Summit (NSS) in New Delhi in January 2012. In these Sherpa meetings, the participant from 49 countries and four international organizations have participated thereby decided the work plans for Nuclear Security in order to protect South Asian Subcontinent. The Sherpas or representatives of the governments have united against nuclear terrorism under the leadership of India. Some of the measures taken include lowering the usage of Highly Enriched Uranium (HEU) and Plutonium as against to TRIGA reactor having $70 \%$ to $93 \%$ enrichment. Also strengthening the protection of nuclear facilities as guided by AERB and preventing the illegal trafficking of nuclear material from source countries such as China has been emphasized, at that time. India has been co-operating proactively with the Interpol's Radiological and Nuclear Terrorism Prevention Unit and the World Customs AntiChinese Organization under the leadership of Defense Minister of India.

The civil nuclear energy sites have been principal attraction of target by terrorists. Like 9/11 attacks with aeroplanes, large release of radioactivity through the disaster to produce significant civilian casualties and land contamination are the main motives of the terrorist groups. In order to provide the highest level of safety against terrorist identified zones (operated by JeM, ISIS, AlQaeda, etc.), computerized 3D carving method has been developed which can carve out containments and other civil structures. The reactor structurals are so strong that they remain intact even during accident scenario such as 9/11 attack with planes. The redundancy of components, on-site availability of spare parts, lead to the mean down time (MDT) of $4 \mathrm{~h}$, that is, $\mathbf{4 . 5 6 6} \times \mathbf{1 0}^{-\mathbf{4}} \mathbf{y}$ and mean time between failures (MTBF) of $37.7 \mathrm{y}$, thus the availability becomes, $\boldsymbol{A}=\frac{\mathbf{1}}{1+\frac{M D T}{M T B F}}=\mathbf{9 9 . 9 9 8 7 \%}$, setting a world record !

\section{Conclusion}

Different reactor accidents at Chernobyl, TMI-2, and Fukushima have been analyzed. From outcomes of these studies, remedy nuclear fuels have been developed at Nuclear Fuel Complex, Hyderabad. The developed nuclear fuels have negative temperature coefficient and larger heat transfer area. Also, these fuels can breed more amount of reusable fissile material for the generation of electricity and process heat. These fuels withstand without failure in accident scenarios due to its relatively low operating temperature in the reactor cores. These safer nuclear fuels are manufactured at Nuclear Fuel Complex, Hyderabad by the Government of India for peaceful civilian usage. All the developed systems either use process heat or electricity generated by nuclear fuels; reducing $\mathrm{CO}_{2}$ emissions into the environment caused by conventional sources of energy.

The indigenously developed BISO and TRISO fuels at BARC have been irradiated and tested in second stage of fast breeder reactor. Developed fuels cannot be melted in reactor hence can withstand extreme temperatures of any postulated accident. All the developed fuels have been utilized in Indian GEN IV reactors. The developed nuclear fuels allow safer co-generation of Electricity and Hydrogen for mobile power plants; eventually taking care of the environment. The process heat available across 
the reactor core has been utilized. The developed 3-D carving method can carve out containments and other civil structures, thereby offers the highest level of safety. Moreover, several medical applications (including that for brachytherapy) have been developed with radioisotopes from spent fuel. The developed reliable nuclear fuels at Nuclear Fuel Complex are useful for safer, peaceful co-generation and environmentally benign applications. Plutonium-239 is also one of the three main isotopes $\left(\mathrm{Pu}^{239}, \mathrm{U}^{233}, \mathrm{U}^{235}\right)$ which can be utilized as fuel in thermal spectrum nuclear reactors. The plutonium inventory can be burned in third stage also. Hence, burning $\mathrm{Pu}^{239}, \mathrm{U}^{233}$ in second or third stage reactors along with Thorium is solution to the nuclear proliferation. Therefore the India's three-stage nuclear power program along with innovative GEN-IV reactors which utilizes the Thorium eliminates nuclear proliferation. The recycling method is very important for energy deficient India.

India has invented and imparted world, the processes to achieve the peace through 3-Stage Nuclear Power Program with its peaceful applications but countries like America \& China are disturbing the peace through the nuclear proliferation. In the history, cyber attacks and proliferation of Indian scientific documents by China, US etc have been experienced in various places in India. US, China, etc have been proliferating hazardous substances to the rest of the world. IAEA member states which are not using above illustrated methods are dangerous in terms of proliferation hence responsible for nuclear proliferation.

\section{ACKNOWLEDGMENT}

I am obliged to Prof. G. D. Yadav from Institute of Chemical Technology for his co-operation on Hydrogen production cycles. We are grateful to reactor physicists from reactor physics division who have provided inputs for AHWR. Thanks to ex-director R. K. Sinha for the innovation of sea water desalination method. Thanks to Dr. Abhay Karandikar and Dr. Timothy A. Gonsalves for cooperation through NETP of IIT Kanpur. Thanks to Prof. M. S. Kalra for his studies on corrections to cross-sections at Massachusetts Institute of Technology and other faculties from NETP of IITK. Thanks to Prof. B. K. Nayak for surrogate method and other staff members from BARC, Mumbai. Appreciations to CEO Sundar Pichai for Google search engine. I extend deep gratitude to world renowned scientific advisor, Prof. C. N. R. Rao.

\section{p.S.}

This paper describes the ideology of Homi J. Bhabha who was selected as President of First International Conference on the Peaceful Uses of Atomic Energy organized by the United Nations at Geneva on August 20, 1955. IAEA member states have deviated from the objectives of this conference jeopardizing India. India's nuclear policy with Three-stage Nuclear Power Program eliminates (closes) the loopholes from the NPT and assist nuclear disarmament. US and China have been proliferating hazardous nuclear materials to the rest of the world.

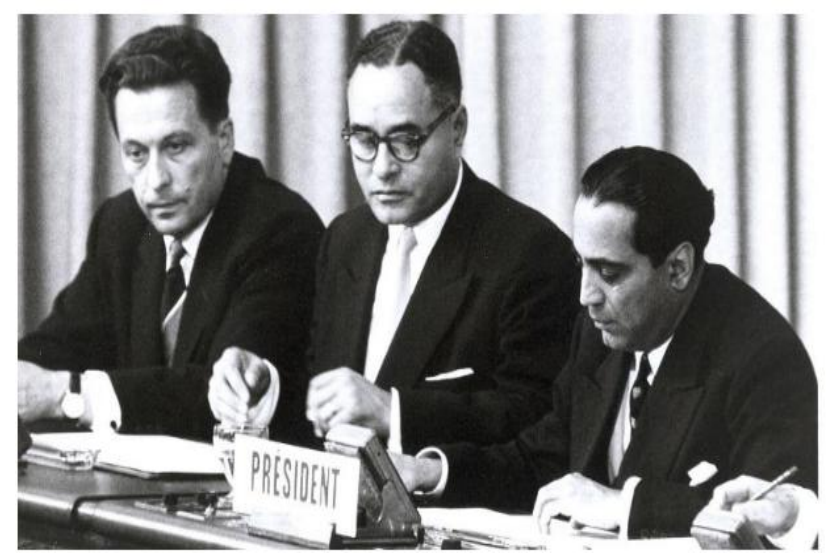

\section{References}

[1] "Chernobyl: The Soviet Report", Nucl. News, (1986),59.
[2] K.D.Badgujar,"System science and control techniques for harnessing nuclear energy", System Sci. Con. Eng., Volume 4, Isssue 1,(2016), pp:138-164.

[3] D.L Hetrick,(1971) "Dynamics of nuclear reactor control", University of Chicago Press, Chicago.

[4] C.D. Fletcher, R. Chambers, M.S. Bolander, and R.J. Dallman," Simulation of the Chernobyl accident", Nucle. Eng. Design, 105,(1988), 157.

[5] H. Mochizuki, "Analysis of the Chernobyl accident from 1:19:00 to first power excursion", Nucl. Eng. Des. 237,(2007),300.

[6] J.F. Aherne.,"Nuclear Power After Chernobyl", Amer.Asso.Adva.Scie.,236,(1987), 673.

[7] F.E. Haskin,A.L. Camp,S.A. Hodge and D.A. Powers,“" Perspectives on reactor safety", NUREG/CR-6042,rev.2, U.S. Nuclear Regulatory Commission (2002).

[8] https://allthingsnuclear.org/dlochbaum/reactor-core-damagemeltdown

[9] J.M. Broughton, P. Kuan, D.A. Petti and E.L. Tolman, "A scenario of Three Mile Island Unit 2 accident," Nucl. Technol. 87,(1989), 34.

[10] T.Hastea,J.Birchleya,E.Cazzolib,J.Vitazkovab,"MELCOR/ MACCS simulation of the TMI-2 severe accident and initial recoveryphases, off-site fission product release and conse quences”, Nucl. En. Des., Vol. 236, Issue 10,( 2006), pp:1099-1112.

[11] “Analysis of Three Mile Island Unit 2 Accident," NSAC-80 (NSAC-1 rev.), Electric Power Research Institute, (1980).

[12] https://www.worldatlas.com/articles

[13] Z. Wu, Y. Cao, S. Nie b, Y. Yang, "Effects of rain on ver tical axis wind turbine performance", Jou. Win. Engi. Ind. Aer. 170, (2017) , pp:128-140.

[14] Department of Atomic Energy, Government of India, Maga zines, March 2016.

[15] A. Saxena,A. Chattergy,R.K. Choudhary,S.S. Kapoor,D.M. Nadkarni, "Entrance channel effects in the fusion-fission time scales from studies of prescission neutron multiplici ties", Phys. Rev. C 49, (1994), 932.

[16] A.P.Deokule , A.K.Vishnoi , K.Umasankari,

D.K.Chandraker, P.K.Vijayan, "Reactor physics and thermal hydraulic Analysis of annular fuel rod cluster for Advanced Heavy Water Reactor", The Fourth International Symposium on Innovative Nuclear Energy Systems, INES-4

[17] K.D. Badgujar, P.K. Vijayan, "Parametric Analysis of Ther mo Siphon Heat Transport Devices", Proceeding of 44th National Conference on Fluid Mechanics and Fluid Power, December 14-17,2017, Amrita University, Amritpuri Cam pus, Kollam, Kerala, India.

[18] P.K. Vijayan, "Experimental observations on the general trends of the steady state and stability behavior of single phase circulation loops", Nucl. Eng. Des. 215, (2002), pp: $139-152$.

[19] J. A. Orzáez, Neutronics analysis of a modified pebble bed advanced high temperature reactor, MS Thesis, The Ohio State University,2009.

[20] https://www.spansen.com/

[21] Compact High Temperature Reactor, Reactor Technology \& Engineering, BARC Highlights.

[22] I.V. Dulera and R..K. Sinha, "The Indian High Temperature Program",IAEA-CN-152,IAEA ProceedingSeries,(2009), pp: 85-93.

[23] P. K. Vijayan, A. Basak, I. V. Dulera1, K. K.Vaze, S. Basu and R. K.Sinha, "Conceptual design of Indian molten salt breeder reactor", Jour. of Phy., Vol. 85, No. 3, (2015), pp: $539-554$.

[24] https://physicstoday.scitation.org/do/10.1063/PT.5.2029/full/

[25] Idelchik, I.E., and Fried, E. Handbook of hydraulic resis tance: Second edition. U.S.: N.p.,1986. Web.

[26] P. K. Netrakanti , V. K. S. Kashyap, D. Mulmule , A. Mitra, V. Jha, D. K. Mishra, S. P. Behera, L. M. Pant, B. K. Nayak, A. Saxena, S. Bhatt, L. M. Pant, S. P. Srivastava, 
"Indian Scintillator Matrix for Reactor Anti-Neutrino detec tion", Journal of Physics: Conf. Series 1216, (2019).

[27] V.Rao, P.R., Chellapandi, P., Srinivasan, e al. "A Perspective on the Indian Programme on Fast Reactors and Associated Fuel Cycles", International Atomic Energy Agency (IAEA): IAEA, (2015).

[28] P. Puthiyavinayagam, P. Selvaraj, V. Balasubramaniyan, S. Raghupathy, K. Velusamy,K. Devan, B.K. Nashine, G. Pad ma Kumar, K.V. Suresh kumar, S. Varatharajan,P. Mohana krishnan, G. Srinivasan, A. K. Bhaduri, "Development of fast breeder reactortechnology in India", Progr. in Nucl. Ener., 101,(2017), pp:19-42.

[29] M. Todosow, A. Aronson, L.-Y. Cheng,R. Wigeland, C. Bathke, C. Murphy, B. Boyer, J. Doyle, B. Fane, B. Ebbing haus, The Indian Advanced Heavy Water Reactor (AHWR) and Non-Proliferation Attributes, Scientific Report,U.S. Department of Energy DOE National Nuclear Security Ad ministration, BNL-98372, (2012).

[30] K. C. Joseph, B. Bharat, H. Parek, M. J. Joshi, "Inhibition of growth of urinary type calcium hydrogen phosphate dihy drate crystals by tartaric acid and tamarind", Current Science,88, (2005), pp:1232-1238.

[31] P. Sinharoy, D. Banerjee, R. Gupta, A. Ananthanarayanan, Ramakant, P. D. Maniyar, J. G. Shah, K. Agarwal, S. Mano har and C. P. Kaushik, Development of ${ }^{106}$ Ru bearing Sealed Source for Eye Cancer Treatment Applications, Research Article, BARC Newsletter.

\section{About Authors}

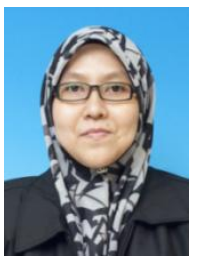

Syazwani Mohd Fadzil completed her MSc from Universiti Kebangsaan, Malaysia, which is the National University of Malaysia. She completed her PhD from POSTECH, South Korea in Vitrification. She has been working as Senior Lecturer in the Department of Applied Physics at Universiti Kebangsaan, Malaysia.

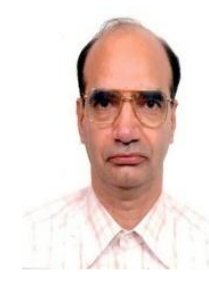

Shafi Qureshi completed his engineering from University of Kashmir. He obtained MS-PhD from University of California, Berkeley. His research interest includes Nuclear Radiation, Detectors and Electronics. Presently, he is working in Electrical engineering department of IIT Kanpur. He has obtained several radiation tolerant patents. $\mathrm{He}$ is also serving as senior IEEE member.

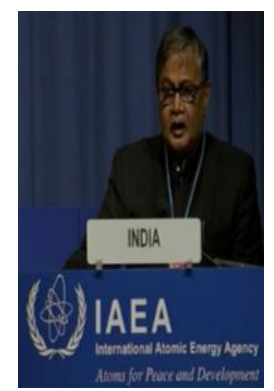

Sekhar Basu is nuclear scientist and presently working as the Chairman, Atomic Energy Commission and Secretary to the Government of India. He has been awarded Honoris Causa Doctorate degrees by eight renowned universities. Under the guidance of Sekhar Basu several mega science projects e.g. High Energy Superconducting Accelerators, Laser Interferometer Gravitational wave Observatory (LIGO), International Thermonuclear Experimental Reactor (ITER), Fission Reactors development have got major boost.
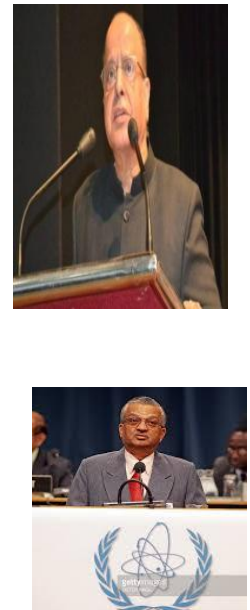

IAEA
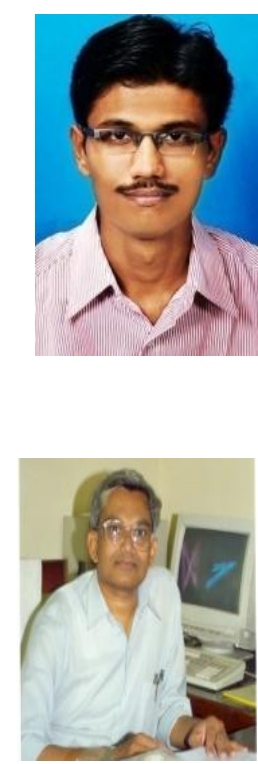

K. Kasturirangan is former of Indian space research organization. Dr Kasturirangan has been the recipient of Honorary Doctorate from 16 universities. More than 244 research papers have been published in the areas of astronomy, space science and applications by him. He is a former member of the Rajya Sabha \& serves as a member of the board of trustees of the Raman Research Institute Trust, Bengaluru.

Anil Kakorkar is nuclear scientist who published more than 250 research articles. He holds many key positions for several committees. He is member of International Nuclear Energy Academy. He is honorary member of the World Innovation Foundation as well. He is also mem ber of the International Nuclear Safety Advisory Group. Also, he is head of rail safety committee.

Kushal D. Badgujar received his postgraduate and doctorate degree in Nuclear engineering from IIT Kanpur and POSTECH, South Korea respectively. He is recipient of best paper award from American Society of Mechanical Engineering (ASME) for his article on Hydrogen Production Using Pebble Bed Reactor in China. Recently, he completed his post-doctorate studies from BARC and working as adjunct faculty in SSVPS at Dhule in India.

Prakash M. Dixit is BTech from IIT Kharagpur. He has expertise in mathematical modeling of accidental scenarios and predicting the solution. He has received Ph.D. in Mechanics from Univ. of Minnesota, Minneapolis, U.S.A. His research interest includes metal forming, large deformation problems, ductile fracture and temperature analysis. 